\title{
WIND PRESSURE ON CIRCULAR CYLINDERS AND CHIMNEYS
}

\author{
By Hugh L. Dryden and George C. Hill
}

\section{ABSTRACT}

In this paper a summary is given of the published model experiments on the wind pressure on cylinders and of some previously unpublished experiments made at the National Bureau of Standards on models, on a large cylinder in natural winds, and on the power plant chimney in natural winds. This information is collected and analyzed for the purpose of estimating the wind pressure on chimneys and other cylindrical structures at known wind speeds.

The new experiments are in large measure determinations of the local distribution of pressure over the entire surface of the cylinder in the model experiments, and over a suitably chosen section in the experiments in natural winds. In addition, the overturning moment on a 10 by 30 foot cylinder in the natural wind was directly measured.

The general conclusions are as follows:

1. The wind pressure on a chimney is a function of the ratio of the height of the chimney to its diameter and possibly of the roughness of the surface.

2. Model experiments can not be directly utilized because of a large scale efiect.

3. A wind pressure corresponding to $20 \mathrm{lbs} . / \mathrm{ft} .^{2}$ of projected arca at a wind speed of 100 miles per hour is a safe value to use in designing chimneys of which the exposed height does not exceed ten times the diameter.

4. The pressure may reach large values locally and this may require consideretion in the design of thin-walled stacks of large diameter.

\section{CONTENTS}

I. Introduction

II. Summary of aerodynamic data on cylinders

III. Model experiments at the Bureau of Standards

1. Apparatus....

2. General procedure

3. Results $\ldots$

4. Discussion and comparison with other published data.

5. Summary of model experiments

IV. Experiments in natural winds

1. The interpretation of experiments in natural winds

2. Experiments on a cylindrical stack, 10 feet in diameter and 30 feet high Distribution of pressure, stack 10 feet in diameter and 30 feet high

(b) Overturning moment, stack 10 feet in diameter and 30 feet high

(c) Summary, stack 10 feet in diameter and 30 feet high_

3. Power-plant chimney

\section{INTRODUCTION}

In Scientific Paper No. 523 of the National Bureau of Standards we have given a general discussion of the wind-pressure problem and of the results of some model experiments on the distribution of pressure over a tall building in a uniform and steady airstream. The experi- 
ments described in the present paper were undertaken for the purpose of obtaining information as to the distribution of wind pressure over chimneys and other structures of substantially cylindrical form.

Because of its great complexity, we have suggested that the windpressure problem be subdivided into several parts, namely, (1) the determination of the wind pressure in a uniform and steady wind, (2) the determination of the frequency of occurrence of winds of specified mean speeds as given by the Weather Bureau records, (3) the determination of the maximum gust speeds in winds of specified mean speeds, and (4) the determination of the stresses produced in the several structural members by specified loadings. The division of the problem into wind loads and wind stresses is well recognized, but the separation of the commonly adopted wind loads into the several components is not often made. Too often a figure of 20,25 , or 30 lbs. $/ \mathrm{ft}^{2}$ is first adopted and then some method of computation is found which will result in the value of the pressure originally adopted and thus in a measure justify its adoption. The loads are often said to correspond to a speed of 100 miles per hour, a figure which seems to be regarded as a limiting value irrespective of exposure.

The problem of choosing a wind speed to be used for design purposes is essentially a problem of probability, and unfortunately there are not sufficient data available to make an exact mathematical study possible. The period of observation for which records are available is not sufficiently extensive to give reliable information regarding the frequency of very high winds. The only records available in sufficient quantity to be useful are those of the Weather Bureau on the mean speeds over 5-minute periods. In many of the records, especially for stations in cities, the exposure and elevation of the anemometer have been occasionally changed, and the records are not comparable for the entire period of years. If we examine the records for a period of years at some station for which the elevation was not changed (for example, for Washington, D. C., for the years 19111927), we find relations somewhat as follows. ${ }^{1}$ The mean speed exceeds 40 miles per hour about 1 day in 85,45 miles per hour about 1 day in 195, 50 miles per hour about 1 day in 850, and 55 miles per hour about 1 day in 1,950. The maximum observed over a period of 58 years was 68 miles per hour, so that the mean speed exceeds 70 miles per hour, say 1 day in 25,000 . The engineer must decide how much risk should be covered in the form of wind-storm insurance rather than in increased strength of construction. If, for example, he decides to design for a load that will occur on the average only once in 20 years, the above figures indicate a mean speed over five minutes in the neighborhood of 60 miles per hour.

The figures published by the Weather Bureau are the uncorrected readings of a Robinson type cup anemometer. Before January 1, 1928, a 4-cup driving unit was used, but on that date a change was made to a 3-cup unit because of the large errors of the older instrument at high speeds. The speeds indicated by the old and the new instruments at various true speeds are given to the nearest mile per hour in Table 1. From the table it is seen that the indicated speed of 60 miles per hour by the old standard corresponds to a true speed of 47 miles per hour.

1 These figures are illustrative only. While approximately correct, they are not intended for use in design. The data are taken from the annual reports of the Chidf of the Weather Bureau. 
TABLE 1.-Indicated wind speeds by Robinson cup anemometers ${ }^{i}$

\begin{tabular}{|c|c|c||c|c|c|}
\hline $\begin{array}{c}\text { True speed } \\
\text { (miles } \\
\text { per hour) }\end{array}$ & $\begin{array}{c}\text { Indicated } \\
\text { speed, old } \\
\text { 4-cup } \\
\text { standard }\end{array}$ & $\begin{array}{c}\text { Indicated } \\
\text { speed, new } \\
\text { 3-cup } \\
\text { standard }\end{array}$ & $\begin{array}{c}\text { True speed } \\
\text { (miles } \\
\text { per hour) }\end{array}$ & $\begin{array}{c}\text { Indicated } \\
\text { speed, old } \\
\text { 4-cup } \\
\text { standard }\end{array}$ & $\begin{array}{c}\text { Indicated } \\
\text { speed, new } \\
\text { 3-cup } \\
\text { standard }\end{array}$ \\
\cline { 2 - 6 } & 5 & 5 & 60 & 78 & 63 \\
10 & 11 & 10 & 65 & 85 & 68 \\
15 & 17 & 15 & 70 & 91 & 73 \\
20 & 23 & 20 & 75 & 98 & 79 \\
25 & 30 & 25 & 80 & 105 & 84 \\
30 & 37 & 31 & 85 & 112 & 89 \\
35 & 44 & 36 & 90 & 118 & 95 \\
40 & 50 & 41 & 95 & 125 & 100 \\
45 & 57 & 47 & 100 & 132 & 105 \\
50 & 64 & 52 & 105 & 138 & 111 \\
55 & 71 & 57 & 110 & 145 & 116 \\
\hline
\end{tabular}

1 Before Jan. 1, 1928, the U.S. Weather Bureau used the 4-cup instrument; after that date, the 3-cup.

Little information is available as to the relation of the speeds of gusts to the mean speed over five minutes. It is commonly assumed that the maximum gust speeds will be about 50 per cent greater than the mean over five minutes, and the few observations which we have made indicate that this is true at speeds below 40 miles per hour and at elevations less than 150 feet above the ground. There is a general belief that in high winds the speed is more uniform, and it is known that the gustiness decreases with increasing elevation. If the engineer assumes that that ratio of the gust speed to the mean speed over five minutes is 1.5, the actual design speed finally arrived at in the above example is 71 miles per hour. We repeat that the figures given are only illustrative of a logical method of procedure and are not intended as design recommendations. Larger values would be found for more exposed locations, such as the New York and Chicago stations.

The work of the Bureau of Standards has been largely confined to a determination of the pressures encountered in a steady and uniform wind, especially as affected by the shape of the body. The results of our experiments are often interpreted in terms of wind loadings at a convenient wind speed, such as 100 miles per hour, and this seems desirable for the benefit of those to whom the concept of force coefficient is new and unfamiliar. We wish to emphasize, however, that our work is concerned with but one element of the problem, and that we do not recommend the indiscriminate use of 100 miles per hour as the wind speed the structure must be designed to withstand. Neither are we in a position to make positive recommendations as to design loads. These should logically depend on the geographical location of the structure and the degree of its exposure, and should be correlated with the working stress and factor of safety used in the design.

\section{SUMMARY OF AERODYNAMIC DATA ON CYLINDERS}

Before making a summary of the published work on cylinders it is necessary to review briefly the conventional method of presenting aerodynamic data. Dimensional reasoning teaches that the pressure, $p$, at any point of a body placed in an air stream will be given by an expression of the form

$$
p / q=f\left(\frac{V L \rho}{\mu}\right)
$$


where $q$ is the velocity pressure $\left(1 / 2 \rho V^{2}\right), \rho$ is the air density, $V$ the wind speed, $\mu$ the viscosity of air, and $L$ a linear dimension fixing the scale, taken as the diameter in the case of cylinders. The expression applies only to geometrically similar bodies, for example, to cylinders of infinite length or of constant ratio of length to diameter. The pressure, $p$, may be regarded as consisting of two parts, the static pressure, ${ }^{2} p_{s}$, which would exist in the absence of the cylinder, and the pressure change, $p-p_{s}$, caused by the presence of the cylinder. In a natural wind $p_{s}$ is the atmospheric pressure. $p-p_{s}$ is the quantity usually measured, corresponding to the common practice of using "gauge" pressure in dealing with pressures in steam boilers, compressed air tanks, etc., rather than absolute pressure. The pressure difference could be measured in any convenient units, but there are advantages in using the velocity pressure, $q=1 / 2 \rho V^{2}$, as the unit. In the first place $\frac{p-p_{s}}{q}$ is in many cases ${ }^{3}$ independent of the wind speed and the size of model, so that from a single value of it for any given shape of body the pressure at the corresponding point on a similar body of any size at any wind speed can be readily computed with the aid of a table of velocity pressures. In many other cases the variation of $\frac{p-p_{s}}{q}$ with the Reynolds number $\frac{V L \rho}{\mu}$ is small. The ratio is a pure number independent of the units used so long as the pressures are all measured in the same units.

\section{TABLE 2.-Velocity pressures at several wind speeds}

\begin{tabular}{|c|c||c|c|}
\hline $\begin{array}{c}\text { True wind } \\
\text { speed } \\
\text { (miles per } \\
\text { hour) }\end{array}$ & $\begin{array}{c}\text { Velocity } \\
\text { pressure } \\
\text { (lbs./ft. }\end{array}$ & $\begin{array}{c}\text { True wind } \\
\text { speed } \\
\text { (miles per } \\
\text { hour) }\end{array}$ & $\begin{array}{c}\text { Velocity } \\
\text { pressure } \\
\text { (lbs./ft. }{ }^{2} \text { ) }\end{array}$ \\
\hline & & & \\
5 & 0.064 & 65 & 10.81 \\
10 & .256 & 70 & 12.53 \\
15 & .575 & 75 & 14.39 \\
20 & 1.023 & 80 & 16.37 \\
& & & 18.48 \\
35 & 1.600 & 85 & 20.72 \\
35 & 2.302 & 90 & 23.08 \\
40 & 4.133 & 95 & 25.58 \\
45 & 5.179 & 100 & \\
50 & 6.394 & 105 & 28.20 \\
55 & 7.737 & 110 & 30.95 \\
60 & 9.208 & 120 & 36.83 \\
& & & \\
\hline
\end{tabular}

NoтE.-Velocity" pressure in Ibs./ft. ${ }^{2}=0.001189\left(V \times \frac{22}{15}\right)^{2}$ where $V$ is the true speed in miles per hour, and the density is that at $15^{\circ} \mathrm{C}$.

The engineer is in most cases more directly concerned with the resulting forces than with the pressures themselves and their distribution. The force on any element, $d A$, is equal to $p d A$ and acts in the direction of the normal to the surface. ${ }^{4}$ If $\theta$ is the angle made by the surface element, $s$, with the wind direction, the component of force in that direction, $F_{s}$, is given by $\int \mathcal{S} p d A$, sin $\theta$. Since $p_{s}$ is

2 The term static pressure is used to indicate tha pressure which would be measured by a pressure gauge moving with the air and, therefore "static" with respect to the air. In actual practice the measurement is made by means of holes in the side of a closed tube, the axis of which is parallel to the wind direction. The form of the tube is such that the air flows smoothly past the holes.

8 B. S. Sci. Paper No. 523, Bull. 20, p. 697.

4 Excluding frictional effects, which are of importance only in special cases. 
constant and for closed surfaces $\int \mathcal{S} d A \sin \theta=0$, the force component for closed surfaces is also given by $\int \mathcal{S}\left(p-p_{s}\right) d A \sin \theta$. Dividing by $q$, we have $\frac{F_{s}}{q}=\iint \frac{p-p_{s}}{q} d A \sin \theta$. It is found convenient to divide this expression by the area of projection, $A_{p}$, of the body on a plane normal to the direction, $s$. The quotient $F_{s} / A_{p} q$ is called the force coefficient. ${ }^{5}$ It is the average force per unit projected area divided by the velocity pressure; that is, the ratio of the average pressure on the total projected area to the velocity pressure. The force in any particular case is obtained by multiplying the force coefficient by the projected area and by the velocity pressure.

In the case of a chimney or similar structure, the distribution of load along the length is sometimes of interest. In this case we compute the force per unit length $\frac{d F_{s}}{d l}=\int p d s \sin \theta$, where $d s d l$ is the area element, $d A$. Again it is convenient to divide $\frac{d F_{s}}{d l}$ by the width of the section (the diameter in the case of a cylinder) and by the velocity pressure $q$ so as to obtain a coefficient applicable to the particular section, giving the average force per unit area per unit velocity pressure. To distinguish this coefficient from the force coefficient applicable to the whole cylinder, we call it the force coefficient for a transverse section. In all cases the force is obtained readily by multiplying the coefficient by an area and by the velocity pressure.

In the case of bodies with sharp edges, such as flat plates, models of buildings, etc., the coefficients defined in this manner are so nearly constant that departures obtained in a few experiments are believed to be due to secondary causes, such as the limited size of air stream used, or the effects of supports. For cylinders and spheres, on the other hand, the coefficients are constant only over a limited range of values of $V L_{\rho} / \mu$. This lack of constancy is called scale effect, since the coefficient varies with the size of the model. Spheres have received the more complete study. It was discovered by Costanzi ${ }^{6}$ for spheres in water and by Eiffel ${ }^{7}$ for spheres in air that the force coefficient for large spheres decreases rapidly at a certain critical speed. Lord Rayleigh ${ }^{8}$ pointed out that the critical speed varied with the diameter of the sphere in such a manner that the Reynolds number was constant. Actually, the critical speed is not a definite fixed speed but rather a range of speeds, corresponding to a certain region of Reynolds number in which the force coefficient decreases rapidly; this is followed by a region in which the force coefficient is fairly constant. In further experiments it was found that the rapid decrease took place at different values of the Reynolds number in different wind tunnels and at different values in the same wind tunnel with different types of spindles or supports. ${ }^{9}$ The degree of turbulence of the air stream was found to be a very important factor.

Additional information was given by Wieselsberger ${ }^{10}$ who showed, by introducing smoke in the air stream, that the turbulent wake was

5 The terms, resistance coefficient, drag coefficient, shape coefficient, are also used.

6 Alcune esperienze di idrodinamica, 2, No. 4; Rome 1912.

7 Comptes Rendus, 155, p. 1597; Dec. 30, 1912.

8 Comntes Rendus, 156, p. 109; Jan. 13, 1913.

${ }^{9}$ See for example the following summaries: Technical Report No. 185, National Advisory Committee for Aeronauties; Reports and Memoranda No. 190, Brit. Adv. Comm. Aero.; Annual Report, Brit. Adv. Comm. Aero., 7, p. 19; 1915-16.

${ }_{10}$ Zeitschrift fur Flugtechnik und Motorluftschifiahrt, 5, p. 140; 1914. 
much smaller above the critical region than below it, and that smooth flow around the sphere continued well past the major section. It was also found that the flow, and hence the force, was most sensitive to disturbances in the "boundary layer" or layer of air passing very close to the sphere, and it was suggested that the change in the general flow at large Reynolds numbers resulted from the flow in this thin layer passing from the smooth viscous flow régime to the turbulent régime, analogous to the change in the type of flow in pipes, first described by Reynolds. ${ }^{11}$

In short, the change in the force coefficient was found associated with a change in the position of the line at which the smooth flow left the surface of the sphere. It may be expected then that no scale-effect would be found in the case of bodies with sharp edges which definitely fix this line, and that spherical and cylindrical forms would be the most sensitive. This is, in fact, the case, as is shown by measurements on ellipsoids by Wieselsberger. ${ }^{12}$ The position of the line of separation in the case of an isolated sphere would be determined solely by the loss of energy in the flow near the surface. This loss depends to a large extent on the turbulence of the air flow, and that is changed by the presence of the rods or wires needed for supporting the sphere.

Similar phenomena are observed with cylinders. Experimental evidence of the existence of a critical region for cylinders was first published by Taylor. ${ }^{13}$ In some measurements on a 6-inch cylinder in a 4-foot wind tunnel he found a large variation of the pressure distribution with wind speed, the nature of which will be discussed later. Force measurements in this region were made subsequently by Eiffel ${ }^{14}$ and by Wieselsberger. ${ }^{15}$

The influence of the flow in the boundary layer and the effect of turbulence were shown experimentally by one of the authors and R. H. Heald. ${ }^{16}$

The force coefficients for cylinders depend on the Reynolds number, the ratio of length to diameter, the turbulence of the air stream, and, perhaps, on the roughness of the surface. The effects of turbulence aro marked only in the region of Reynolds numbers between 100,000 and 500,000. Figure 1 gives the results of Relf ${ }^{17}$ and Wieselsberger ${ }^{18}$ for. cylinders of infinite length (actually of finite length, but under conditions approximating two dimensional flow) over a wide range of Reynolds number. These values may be used in computing the wind pressure on long wires, masts, flagpoles, and similar structures. For this purpose the kinematic viscosity (the ratio of the viscosity, $\mu$, to the density, $\rho$ ) may be assumed to bo $0.000161 \mathrm{ft}^{2} / \mathrm{sec}$. and the Reynolds number taken equal to the product of wind speed in miles per hour by diameter of cylinder in feet by the constant 9,100 .

Wieselsberger gives some information as to the variation of force coefficient with length-diameter ratio at a Reynolds number of 80,000 . The values are given in Table 3.

1 Phil. Trans. Roy. Soe. (London), 174, Pt. III, p.935; 1883. For a further dovelopment of these ideas, see Technical lieport 342 of tho National Advisory Committe for Aeromatics.

12 7.eitschrift fur Flugtechnik und Motorluftschifinhrt, $5, \mathrm{p}, 140 ; 1914$.

13 Reports and Memoranda. No. 191, 13rit. Adv. Comm. Aern. Annual Report, 7. p. 30; 1915-16.

14 'Tavaux Iaboratoire Aerodynamique kithel (E. Chirn, Paris), p. 60, 1915-1918.

15 Ergebnisse der Aerodynamischen Versuchsanstalt, (iötingen, ig23 (1R. Oldenbourg), $2, \mathbf{p .} 23$.

16 'Technical Report No.231. National Advisory c'ommitee for ieronautics.

17 IReports and Mlemoranila No. 102, Brit. Adv. Coumn. Acro. Anmual Report, 5, p. 47; 1913-14,

18 l'hysikalischo Zeitschrift, 23, p. 219; 1922. 
TABLE 3.-E:fect of length-diameter ratio on force coefficients of cylinders al a Reynolds number of 80,000

$\begin{array}{lcccccccc}\text { Length-diameter ratio_._. } & 1 & 2 & 3 & 5 & 10 & 20 & 40 & \infty \\ \text { Force coefficient__._._. } & 0.63 & 0.69 & 0.75 & 0.74 & 0.83 & 0.92 & 1.00 & 1.20\end{array}$

The cylinders of length-diameter ratios 5 and $\infty$ were carried through a wide range of Reynolds numbers and a comparison of the results seems to indicate a smaller eflect of length-diameter ratio above the critical region.

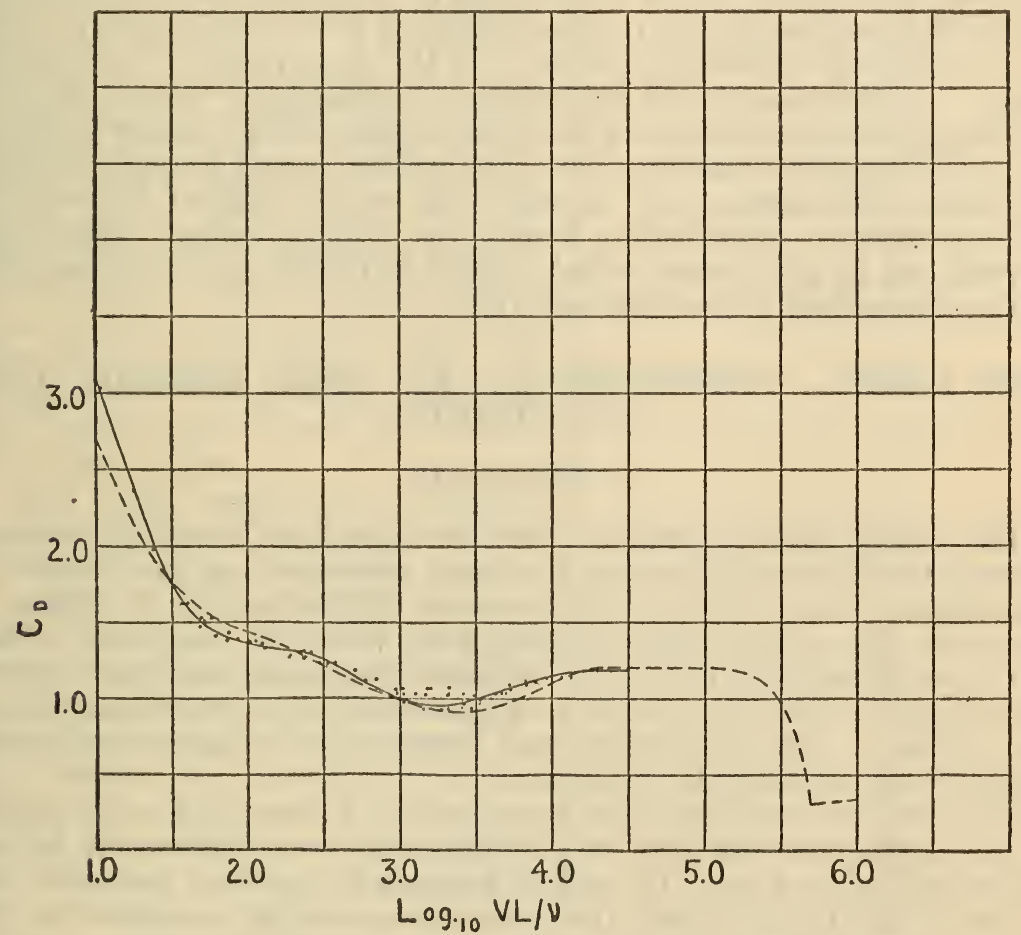

Figure 1.-Force coeffcients for cylinders of infinite length

$C_{D}=$ force coefmicient.

$V=$ wind speed (ft./sec.).

$L=$ diameter (ft.).

$\nu=$ kinematic viscosity (ft. $2 /$ sec.).

$=0.000161$ for air.

Relf.

Wieselsberger.

In addition to measurements of the total force on the whole cylindor, a number of measurements of the distribution of piessure around the cylinder have been published. These experiments will be summarized and discussed a little later in connection with the results described in this paper.

Several important investigations relating to the flow around cylinders have also been published. For Reynolds numbers between 100 and the critical value, the flow is known to vary with the time, eadies breaking off periodically. The frequency of the eddy formation has 
been studied by Karman ${ }^{19}$ and Relf. ${ }^{20}$ For approximate computations at Reynolds numbers below the critical value the product of frequency (cycles per second) by diameter of the cylinder (in feet) may be taken as 0.29 times the wind speed in miles per hour. At the critical Reynolds number the frequency increases more rapidly with the speed, and finally the flow loses its periodic character; it continues to vary with time, but in an erratic manner. It is obvious that conditions of resonance in wires or flagpoles in high winds are to be avoided, and it seems probable that the erratic fluctuation of the flow may set up severe oscillations in chimneys of small stifiness.

Model experiments fail to give values of force coefficients applicable to full-scale chimneys, because of the occurrence of the critical region. Furthermore, the information available as to the effect of the length-diameter ratio and as to the details of the pressure distribution at Reynolds numbers above the critical value is quite limited. Our first experiments were intended to supply further information on the pressure distribution above the critical value. They were carried out in the 10-foot wind tunnel of the Bureau of Standards and are described in the next section.

\section{MODEL EXPERIMENTS AT THE BUREAU OF STANDARDS}

\section{APPARATUS}

The distribution of pressure over two circular cylinders with axes normal to the wind direction has been measured at the Bureau of Standards. One of the cylinders was approximately 8 inches in diameter, the other approximately 12.6 inches in diameter. Each was approximately 5 feet long. Observations were made at 12 pressure stations, spaced as shown in Figure 2, along a generating line of the cylinder. The circumferential distribution at each station was obtained by rotating the cylinder.

The pressure stations were prepared as follows: At each station a hole approximately 0.2 inch in diameter was drilled. A hollow cylindrical plug about $1 \frac{1}{4}$ inches long and closed at one end was sweated into the hole and the closed end carefully worked down so as to make it flush with the outer surface of the cylinder. After polishing, a small hole approximately 0.040 inch in diameter was drilled along the axis of the plug into the tubular portion. By means of rubber tubing, connection through the interior of the cylinder could then be made from each station to the pressure gauge.

The same mounting was used for the 8-inch cylinder as for the prism described in Scientific Paper No. 523. The cylinder was rigidly attached to a round steel plate, 12 inches in diameter and $1 / 4$ inch in thickness, bearing graduations at $5^{\circ}$ intervals along its circumference. The cylinder and plate could be rotated on a bearing fastened to a plate 14 inches square and $3 / 8$ inch thick, which carried an index mark. The cylinder proper was a piece of drawn brass tubing, 4 feet $11 \%$ inches long, and was accurately a circular cylinder within \pm 0.04 inch. The departures were greatest near one end (the upper), and

10 Physikalische Zeitschrift, 13, p. 49; 1912.

${ }_{20}$ Phil. Mag. (Bth series), 42, p. 173; 1921. Reports and Menorand ${ }^{2}$ of the British Aeronautical Research Committee, Nos. 825,917 , and 986. 
over the greater part of the length were less than 0.015 inch. The top of the cylinder was closed by a plate $3 / 16$ inch thick. The total length from the bottom of the mounting to the top of the top plate was 5 feet $9 / 16$ inch, of which $5 / 8$ inch was taken up in the mounting plates.

The 12.6-inch tubing was more accurately of the form of a circular cylinder. The average diameter was 12.62 inches with departures less than \pm 0.01 inch. A somewhat heavier mounting was required; the upper plate to which the cylinder was attached was 15 inches in diameter and $1 / 2$ inch thick, and the lower plate carrying the bearing was $17^{3 / 4}$ inches in diameter and $1 \frac{3}{3 / 8}$ inches thick. The cylinder proper was exactly 5 feet long and the top plate was $1 / 8$ inch thick. The total length was 5 feet 2 inches, of which $17 / 8$ inches was taken up in the mounting plates.

The wind stream was supplied by the 10-foot wind tunnel which is described in Scientific Paper No. 523. The method of measuring wind speed and the pressure gauge used for measuring pressures at the station on the cylinders were described in the same paper. In the present tests speeds up to about 66 miles per hour were obtained.

The effect of the ground on which the chimney stands was simulated by a platform placed under the model. The platform extended completely across the tunnel and was 2 feet above the tunnel floor at the center. Its length in the direction of the wind was 5 feet and its upstream edge was beveled so as to reduce the disturbance produced by it. The wind speed was nearly uniform to within a few inches of the platform.

\section{GENERAL PROCEDURE}

The procedure for making the observations was as follows: The

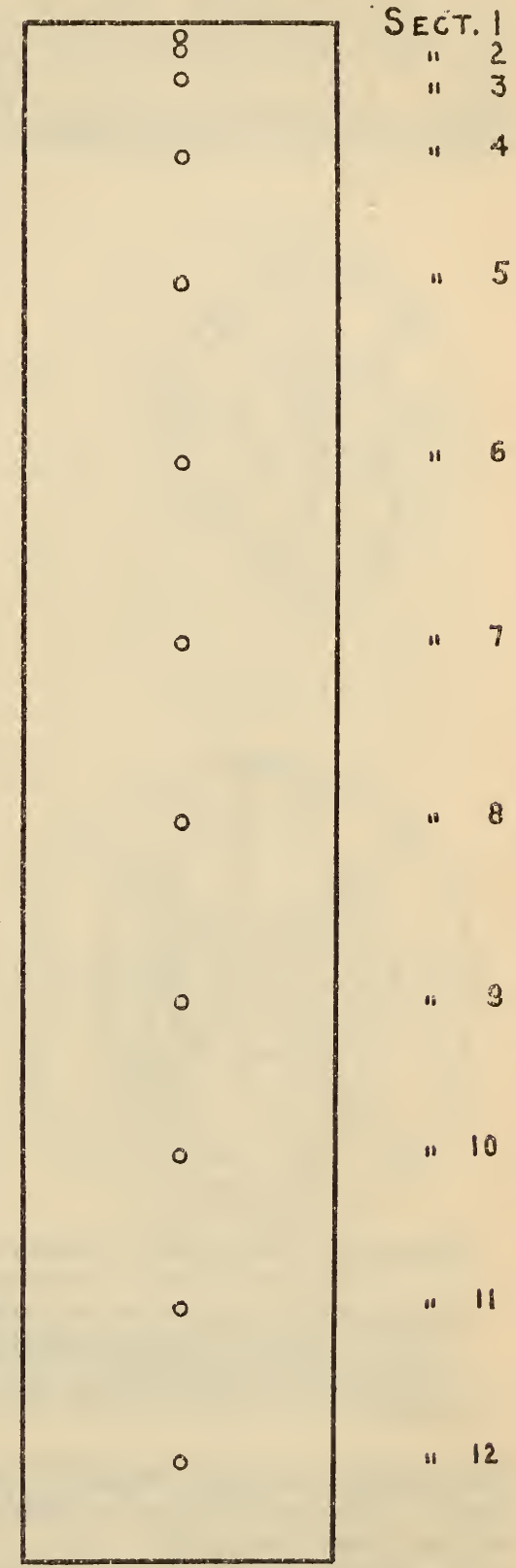

Figure 2.-Location of pressure stations on cylinders in wind-tunnel tests

12 pressure stations were connected to 12 tubes of a multiple tube manometer, the reservoir of the manometer being connected to a 
smail hole in a static plate located $7 \frac{3}{4}$ feet upstream from the model or, on some occasions, to a small hole in the downstream quadrant of a short cylinder placed with axis normal to the wind. ${ }^{21}$ When the wind speed was steady, an observer read the 12 tubes of the multiple gauge, which gave the differences in pressure between the holes at the surface of the model and the reference pressure. Readings were taken for speeds of approximately 40,60, 80, and 97 feet per second.
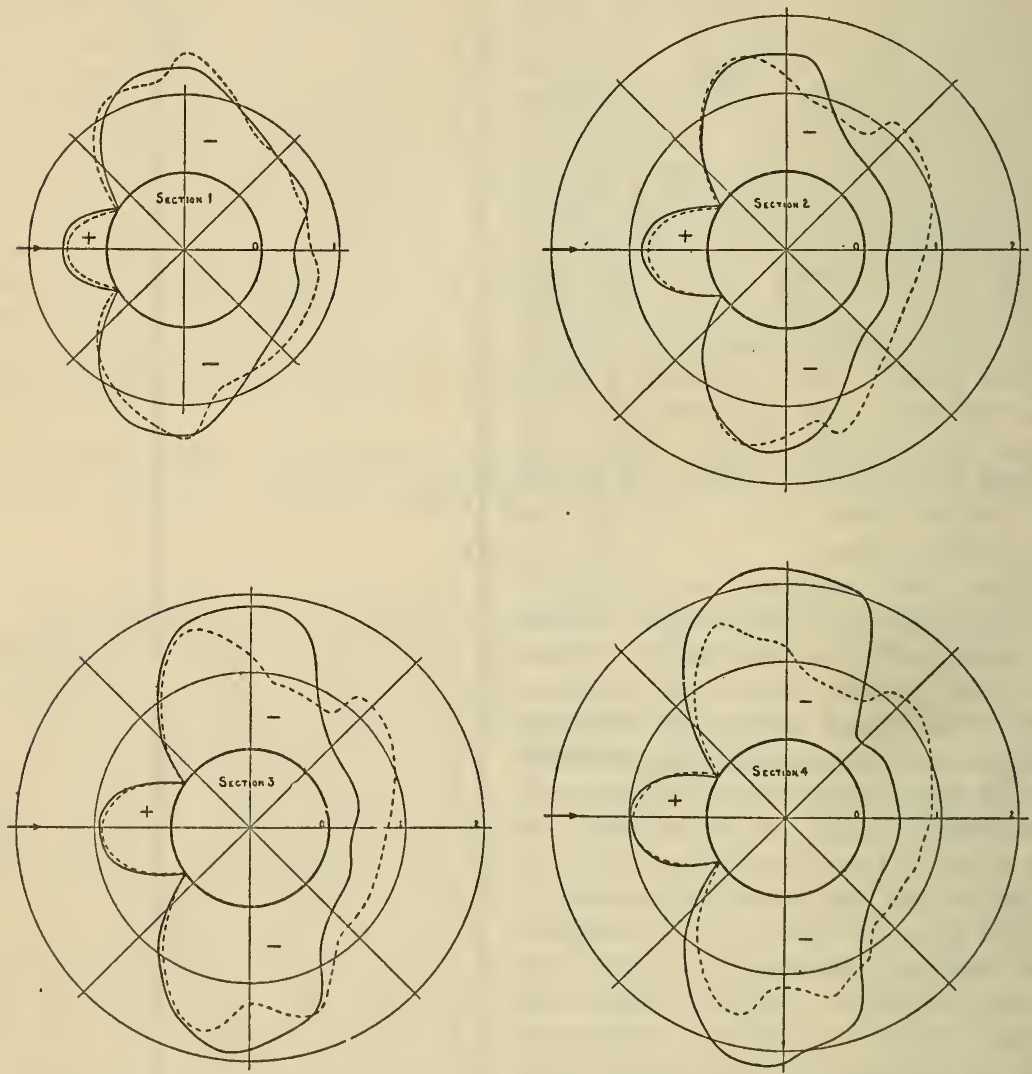

Figure 3.-Distribution of pressure on 8-inch cylinder at sections 1, 2, 3, and 4

Radial"distances from the base circle are proportional to the ratio to the velocity pressure of the difference in pressure between the station and the static pressure. In the region marked + , the pressure on the cylinder exceeds the static pressure, while in the region marked - , the pressure on the cylinder is less than the static pressure. The wind direction is shown by the arrow. The broken line is for a speed of $40 \mathrm{ft}$./sec., the solid line for $80 \mathrm{ft}$./sec. See Figure 2 for location of sections.

The cylinder was then turned $5^{\circ}$ and a similar group of measurements made. The process was continued until the full angular range of $360^{\circ}$ had been covered.

The results finally desired are the changes in pressure produced by the presence of the cylinder. It was necessary, therefore, to measure the diflerence in pressure between the reference pressure and the

21 This was done in order to keep the differential pressure within the range of the multiple manometcr. 
static pressure in the tunnel at the place previously occupied by the cylinder and to add this value with proper sign to the observed pressure. It was also necessary to correct for the difference in wind speed between the place where the reference Pitot-static tube was located and the position of the model.

All results in this paper have been expressed as ratios of the several quantities to the velocity pressure, a plus sign being used to denote
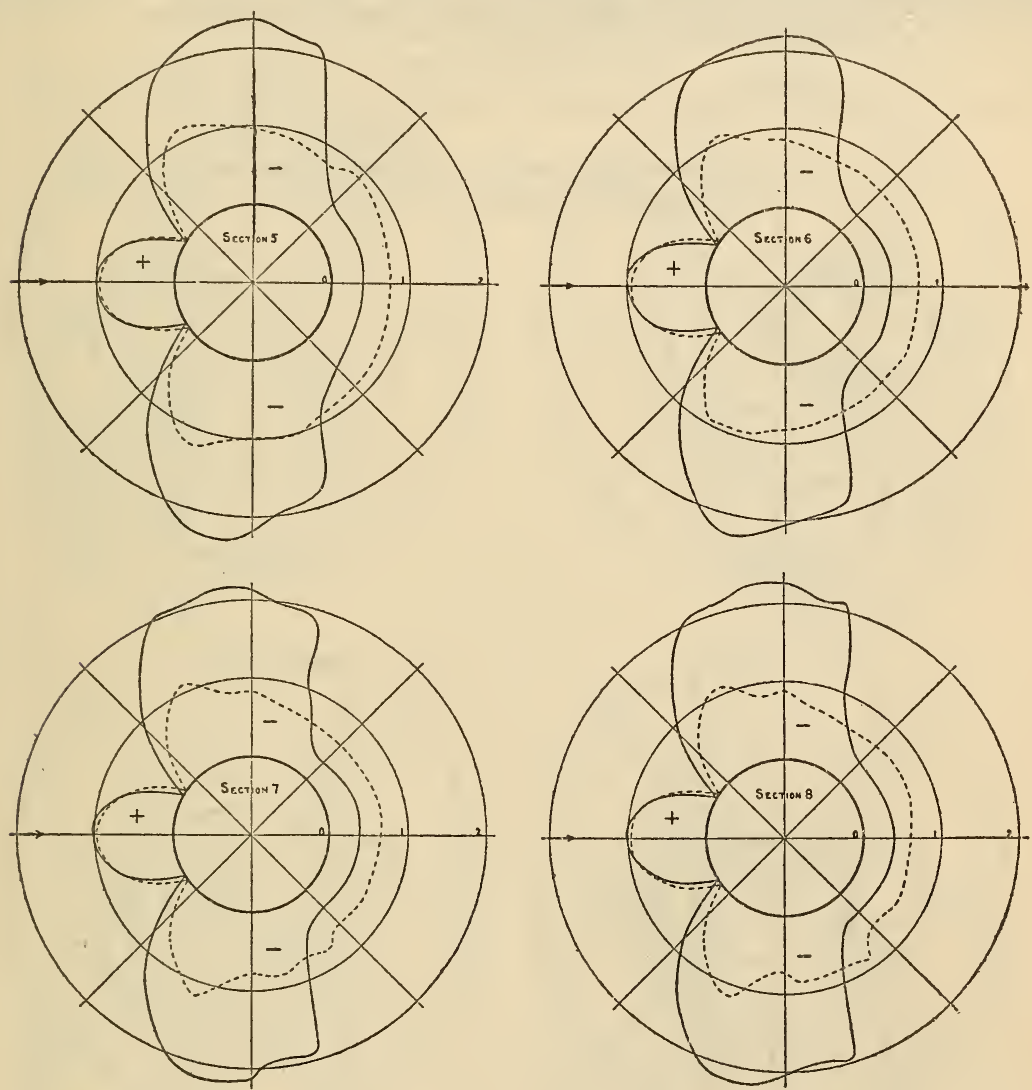

FIGURE 4.-Distribution of pressure on 8-inch cylinder at sections 5, 6, 7, and 8

For explanation, see legend of Figure 3

an increase in pressure above the static pressure and a minus sign to denote a decrease.

The average pressure acting at each section on the area of projection of the cylinder on a plane normal to the wind and the average pressure acting on the entire cross-sectional area were each computed by numerical integration. These results give the load distribution along the length and the total force on the cylinder. Resultant forces at right angles to the wind direction are small and would be exactly zero if the pressure distribution were exactly symmetrical. 


\section{RESULTS}

The pressure distribution for the four air speeds are given in part in the polar diagrams of Figures 3 to 8 , inclusive. The distributions of average force per unit projected area along the length aro given in Figures 9 and 10 and the average force per unit projected area for the whole cylinder in Figure 11 . The quantities plotted are absolute coefficients, the values of which do not depend on the system of units, provided a self-consistent system is used throughout.
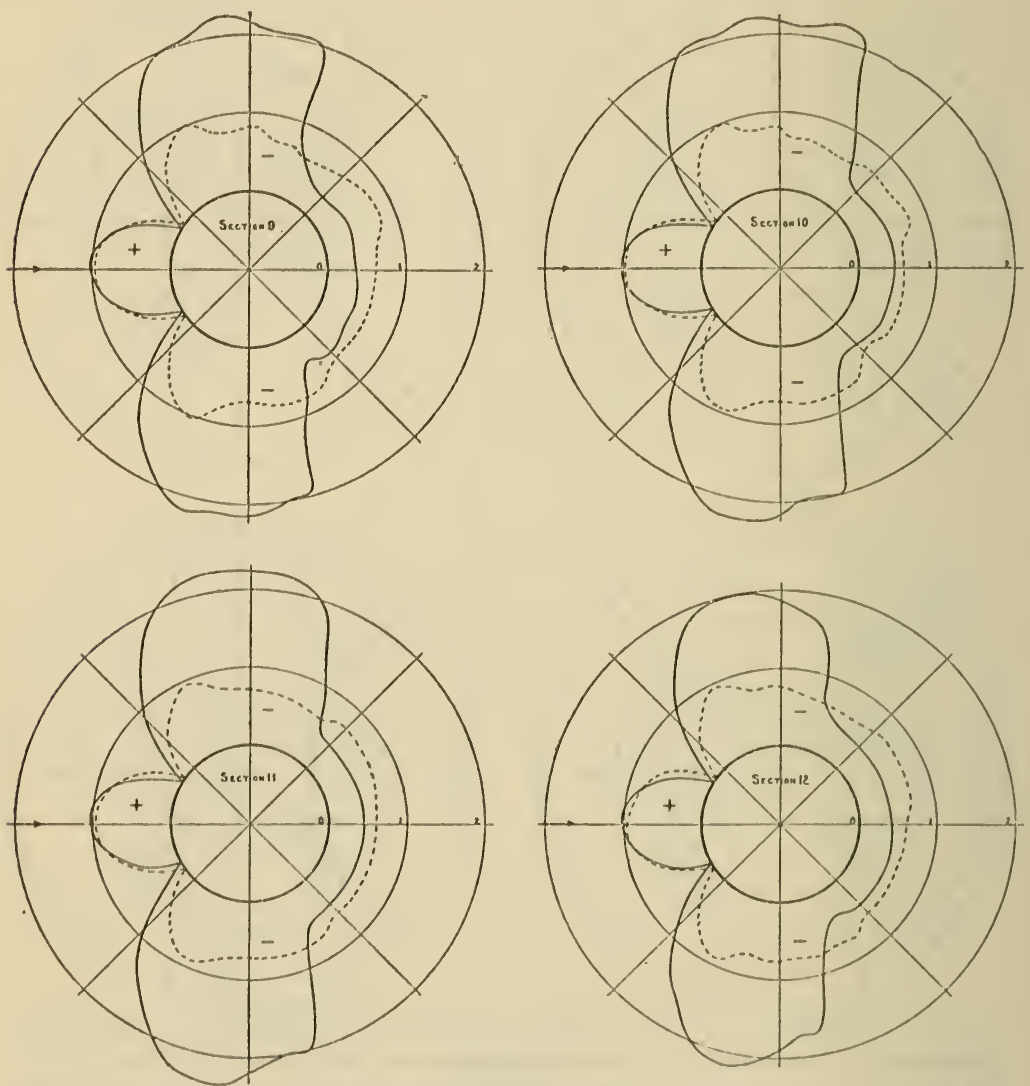

Figune: 5.-Distribution of pressure on 8-inch cylinder at sections 9, 10, 11 , and 12

For explanation, sce Figure 3

The coefficients are defined as follows:

$$
C^{\prime}{ }_{D} \text { at any section }=\frac{1}{w} \int \frac{p-p_{s}}{q} \sin \theta d s
$$

$C_{D}$ for the whole cylinder $=\frac{1}{w l} \int \frac{p-p_{s}}{q} \sin \theta d s d l=\frac{\text { total force }}{w l_{q}}$ 
where $w=$ width of projection on a plane normal to the wind=diameter of cylinder.

$l=$ length of the cylinder.

$d s d l=$ element of area on the surface of the cylinder. (Note that $d s \sin \theta=d w$.)

$\theta=$ angle between the surface element of the cylinder at any point and the wind direction; that is, the complement of the zonal angle, $90^{\circ}$ - the zonal angle, of the station measured from the upstream generating line.

$q=$ the velocity pressure (Table 2 ).

$p-p_{s}=$ the difference between the pressure at any station and the static pressure.

$C^{\prime}{ }_{D}=$ force coefficient for transverse section.

$C_{D}=$ force coefficient for whole cylinder.
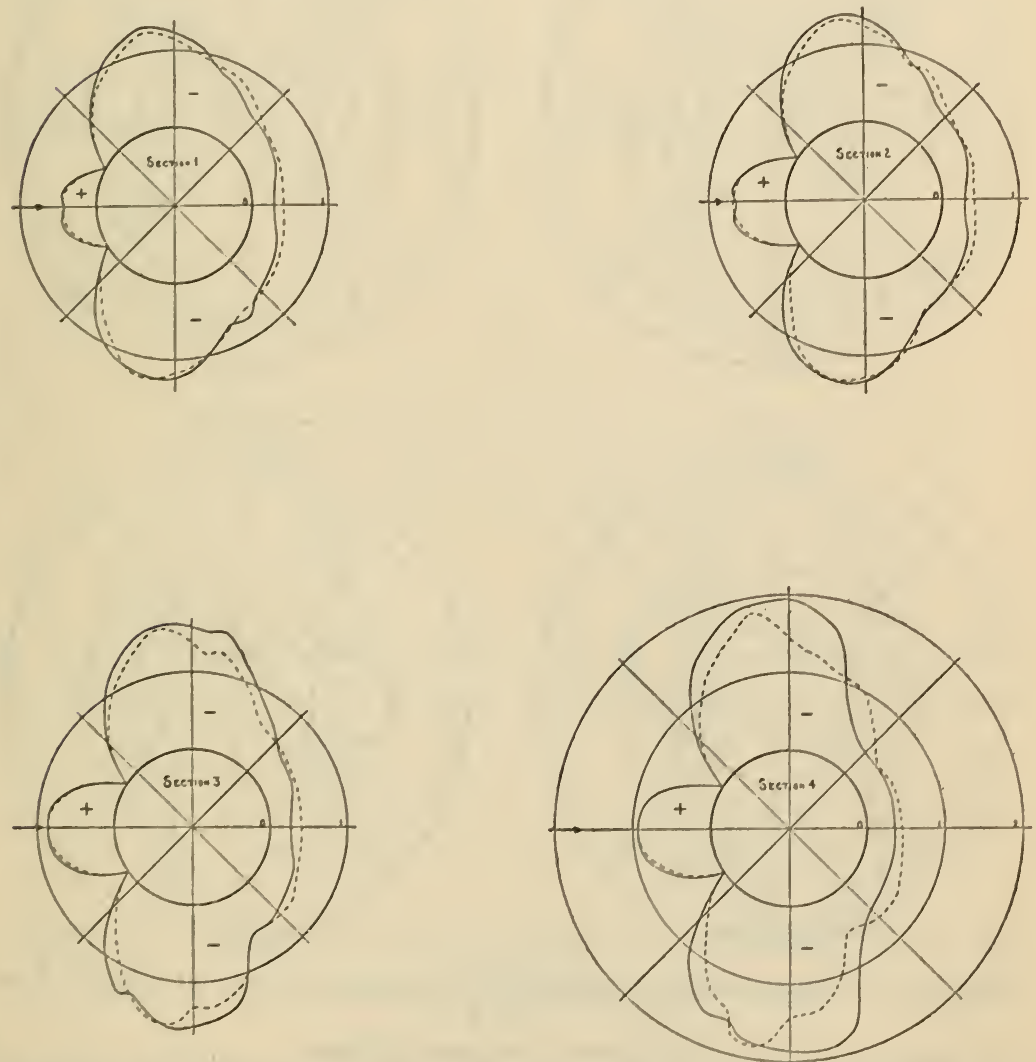

FIgURE 6.-Distribution of pressure on 12.6-inch cylinder at sections 1, 2, 8, and 4

For explanation, sce legend of Figure 3

The force per unit length at any section is obtained by multiplying the value of $C^{\prime \prime}{ }_{D}$ at that section by the width of the section and the velocity pressure. The total force is obtained by multiplying the value of $C_{D}$ for the whole cylinder by the area of projection on a plane normal to the wind, that is $v y l$, and the velocity pressure. 
It will be seen that all of the coefficients vary greatly with the wind speed, differing in this respect from those for the prism model of Scientific Paper No. 523. Dimensional reasoning teaches, as indicated before, that provided the objects are geometrically similar the pressure should be a function solely of the Reynolds number, $V L \rho / \mu$, $V$ being the wind speed, $L$ a linear dimension fixing the scale and taken equal to the diameter, $\rho$ the density and $\mu$ the viscosity of the air. The two cylinders are not geometrically similar to each other; nevertheless at high Reynolds numbers the results for the two agree fairly well. (See fig. 11.)
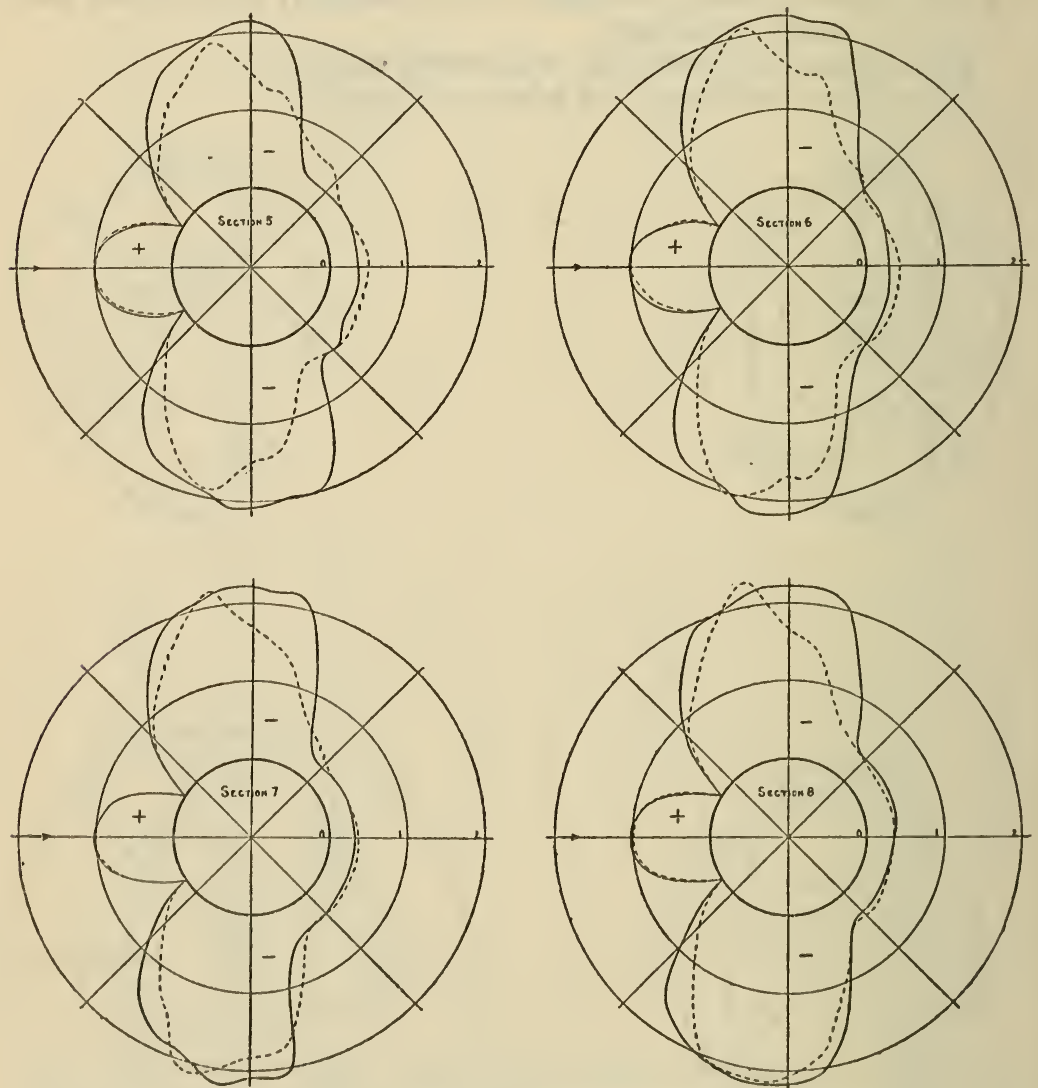

FiguRe 7.-Distribution of pressure on 12.6-inch cylinder at sections 5, 6, 7, and 8

For explanation, see legend of Figure 3

\section{DISCUSSION AND COMPARISON WITH OTHER PUBLISHED DATA}

All of the speeds used for the 8-inch cylinder aro equal to or greater than the critical value. Because of this fact the computation of averago pressures is subject to a small error. For, owing to changes in the barometric pressure and the temperature of the air, the linematic viscosity and, hence, the Reynolds number for a given air speed changes from day to day. The total rango in values of the 
Reynolds number at a given speed was about 3 per cent. The effect on the value of the average pressure is probably not very great.

A careful examination of the diagram shows a lack of symmetry with respect to the wind direction. By reading off the angles at which $p-p_{s}$ vanishes we may estimate the nature and amount of the asymmetry. Figure 12 shows the average angle of asymmetry or angle through which the diagram for each section must be rotated to bring the points of zero pressure difference to symmetrical positions.
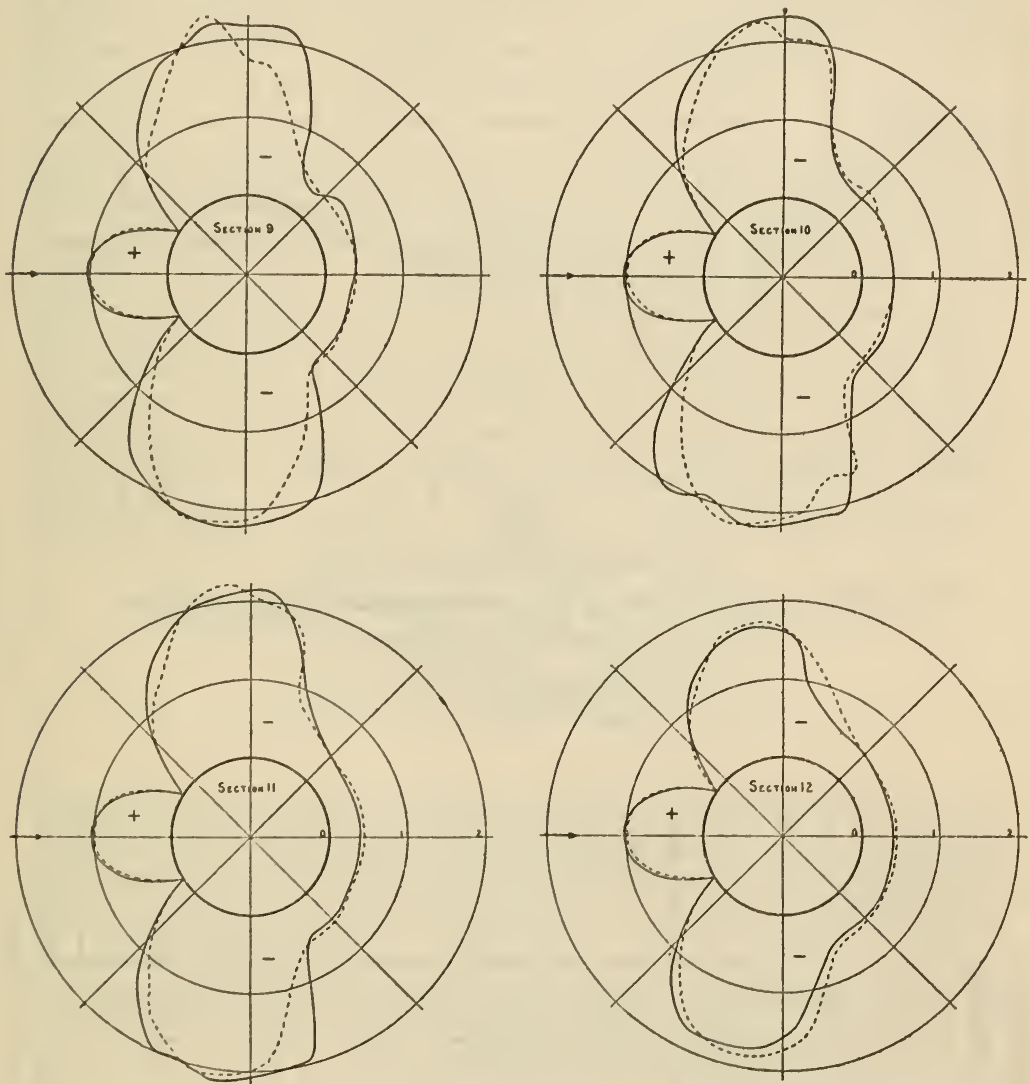

FIGURE 8.-Distribution of pressure on 12.6-inch cylinder at sections 9, 10, 11 , and 12

For explanation, see legend of Figure 3

The figure shows a systematic and approximately linear variation of roughly $1 / 2{ }^{\circ}$ per foot of height corresponding to a rotation in the direction of travel of the propeller blades. Measurements in the absence of the cylinders with an instrument for measuring the direction of air flow show a spin in the air stream of about one-half this amount.

The projected area of the 12.6-inch cylinder was about 7 per cent of the tunnel area, and that of the 8 -inch cylinder about $4 \frac{1}{2}$ per cent of the tunnel area. The only experiments available on the effect of tunnel size are those of Parkin ${ }^{22}$ and they are based on the theory 


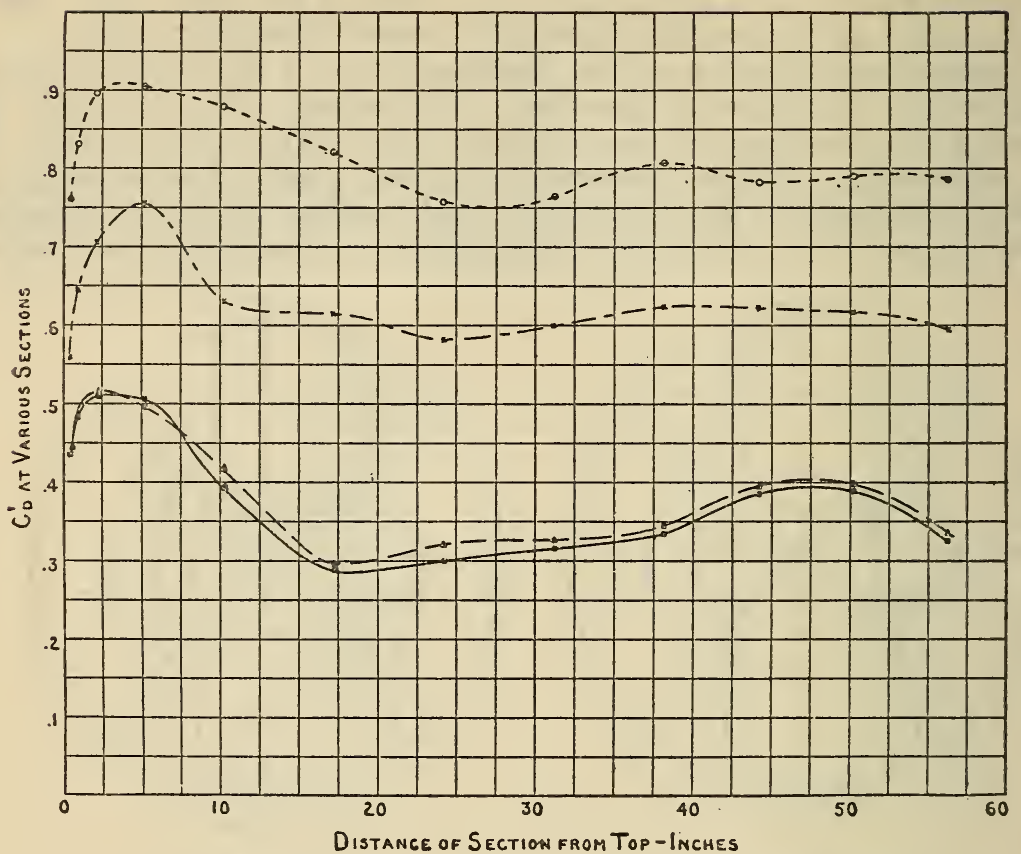

FigURE 9.-Distribution of pressure along the 8-inch cylinder

$\mathrm{C}_{D^{\prime}}=$ force coefficient for transverse section-

- - - $-40 \mathrm{ft} . / \mathrm{sec}$.

- - $60 \mathrm{ft} . / \mathrm{sec}$

$--97 \mathrm{ft} . / \mathrm{sec}$.

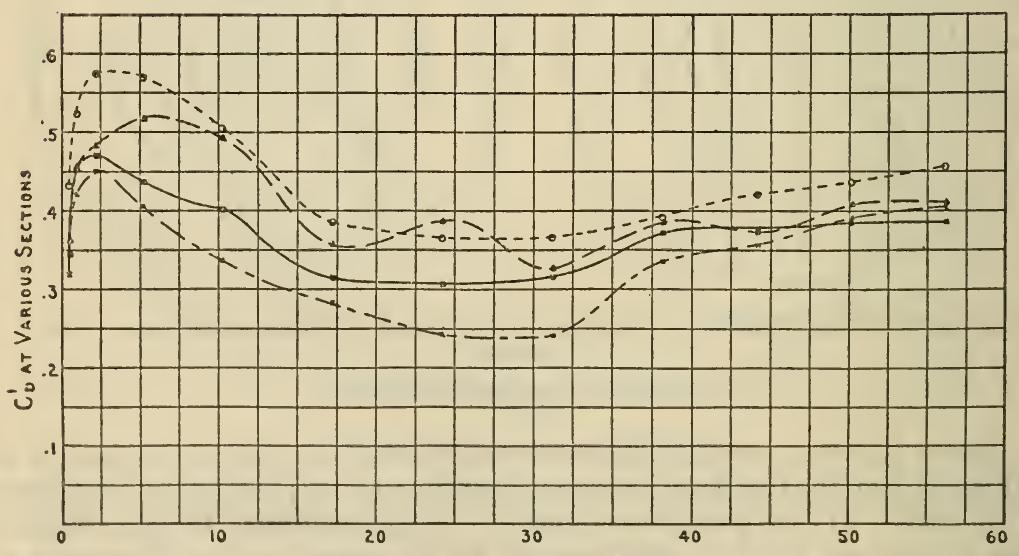

Distance of Section from Top-Inches

Fiaure 10.-Distribution of pressure along the 12.6-inch cylinder

$\mathrm{C}_{D^{\prime}}=$ force coeficient for transverse section-

- - - $40 \mathrm{ft} . / \mathrm{sec}$.

$-\longrightarrow-1 \mathrm{ft} . / \mathrm{sec}$.

$-10 \mathrm{ft} . / \mathrm{sec}$

- - - - $97 \mathrm{ft} . / \mathrm{sec}$. 


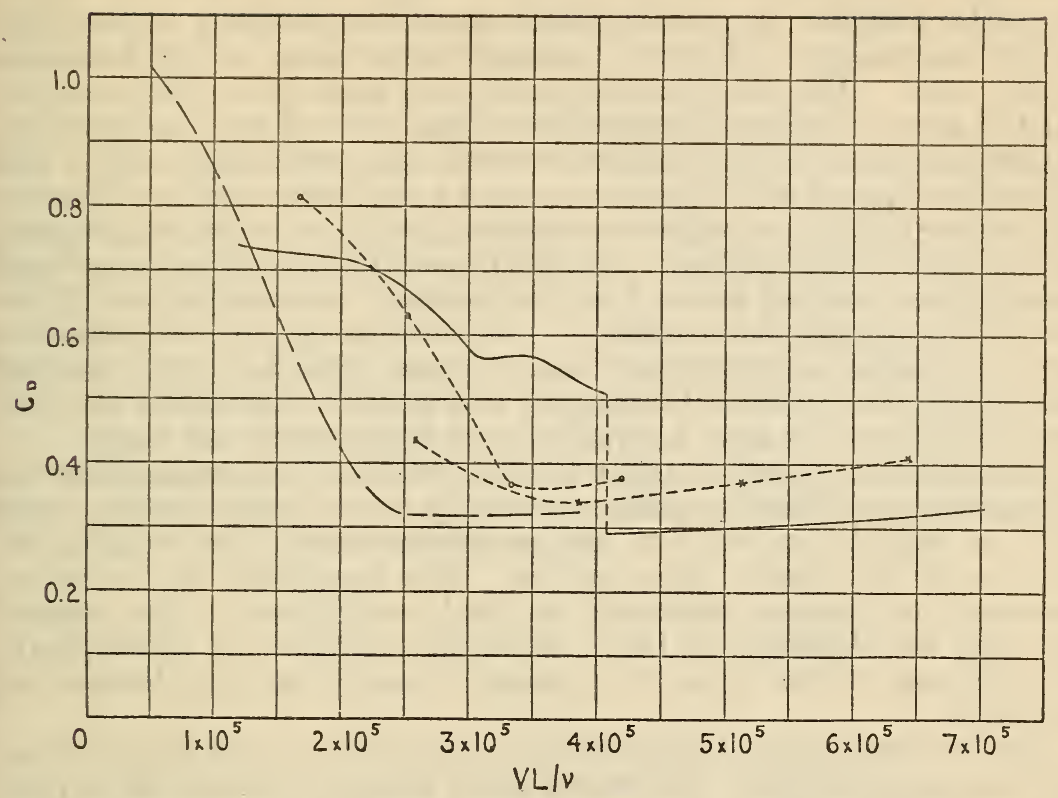

FigCRE 11.-Force coefficients for cylinders at large Reynolds numbers $C_{D}=$ force coefficient (for the whole cylinder).

$V=$ wind speed (ft./sec.).

$L=$ diameter (ft.), $\nu=$ kinematic viscosity $\left(\mathrm{ft} .{ }^{2} / \mathrm{sec}.\right)=0.000161$ for air.

Eiffel.

o - - - Dryden and Hill, 8-inch cylinder.

צ- - - Dryden and Hill, 12.6-inch cylinder.

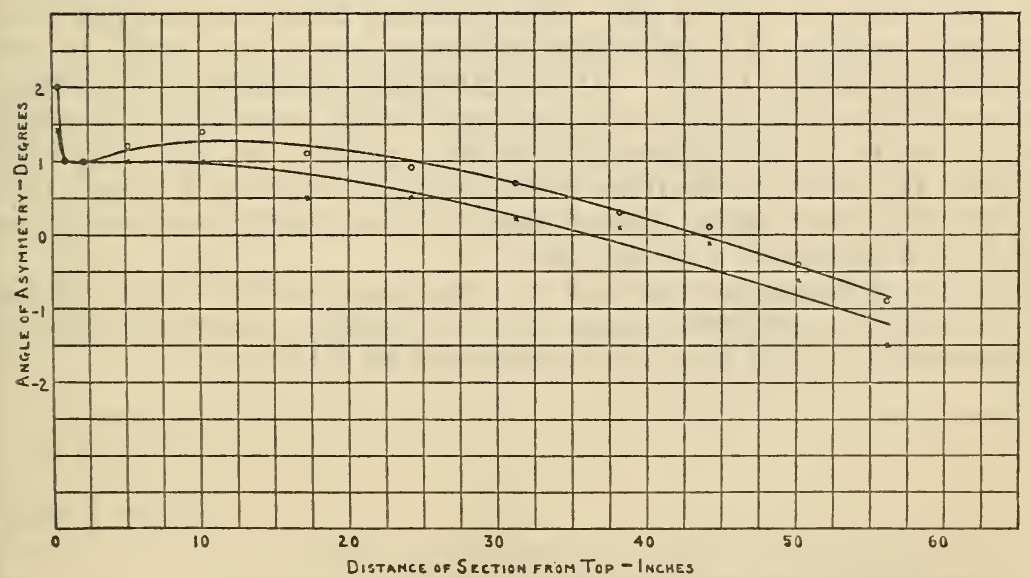

FIGURE 12.-Angle through which the pressure diagrams for the various sections must be rotated in order to give symmetrical positions for the points of zero pressure difference 
of images. In other words, the tests actually made were on a cylinder in the presence of other cylinders placed in positions corresponding to the images of the first cylinder in the walls of the fictitious small tunnel. The smallest projected area was about 1.8 per cent and the next was about 35 per cent of the area of the tunnel cross section, so that it is not possible to estimate very closely where the effect of the tunnel walls begins to exceed a predetermined small value. The values of the ratio which we have employed are in line with values used in other laboratories. At Göttingen the projected area was about 11 per cent and at the Eiffel Laboratory about 9 per cent of the area of the tunnel cross section. The ratio of cylinder diameter to tunnel diameter was 0.105 for the 12.6-inch cylinder, 0.067 for the 8-inch cylinder, 0.134 at Göttingen, and 0.100 at the Eiffel Laboratory. Taylor states that a ratio of 0.125 is evidently too large.

We recognize, therefore, that the conditions of the experiment do not correspond to ideal conditions as fully as one might desire, especially as regards the ratio of the projected area of the cylinder to the area of the tunnel cross section. The conditions do, however, represent the nearest approach to ideal conditions in this respect that can be obtained at large Reynolds numbers in atmospheric wind tunnels of the sizes at present available at the Bureau of Standards.

The observed type of distribution of pressure is well known from previous measurements, differences being matters of detail as to relative numerical values. In every case except for sections 1 to 4 , which are in the uppermost 5 per cent of the length, the maximum pressure increase on the front is equal to the velocity pressure within 2 per cent, hence within the experimental error. The point of maximum pressure is within $1^{\circ}$ of the point farthest upstream and the variations within this limit which have been previously discussed are at least partly due to a slight spiral motion in the air stream. The pressure falls off to either side and reaches the static pressure at a zonal angle of from $31^{\circ}$ to $35^{\circ}$. The pressure then becomes less than the static pressure by increasing amounts up to an angle in the neighborhood of $65^{\circ}$ to $75^{\circ}$. At low Reynolds numbers, the pressure decrease drops slightly from its maximum value near $70^{\circ}$ to a nearly constant value extending from $85^{\circ}$ or $90^{\circ}$ to $180^{\circ}$. At high Reynolds numbers, the pressure decrease varies slightly between $70^{\circ}$ and $100^{\circ}$ or $100^{\circ}$ and then drops rather sharply to a nearly constant value extending from about $135^{\circ}$ to $180^{\circ}$.

The chief differences observed over the range of Reynolds number from 168,000 to 642,000 (most of the change occurring between 252,000 and 257,000 ) may be summarized as follows:

1. Zonal angle at which the pressure is equal to the static pressure
2. Maximum pressure decrease below the static pressure, expressed as a ratio to the

2. Maximum pressure
velocity pressure.

3. Mean pressure decrease over rear quarter of cylinder, expresied as a ratio to the velocity pressuro.

Reynolds No.

\begin{tabular}{r|r}
168,000 & 642,000 \\
\hline $35^{\circ}$ & $31^{\circ}$ \\
1.2 & 2.4 \\
.7 & .4 \\
\hline
\end{tabular}


These changes, especially the last two, are well shown in Figures 3,4 , and 5 . The excessive development of the winglike protuberances extending across the direction of the air stream are characteristic of Reynolds numbers above the critical value.

Table 4 gives all of the published information which we have been. able to find on the general characteristics of the pressure distribution around circular cylinders. As it seems probable that a cylinder spanning an open air stream does not act as a cylinder of infinite length (owing to the feeding of air into the low pressure regions at its ends), the results of Hemke (serials 15 and 16) and of Toussaint and Weisenburger (serial 17) have been considered applicable to cylinders having lengths equal to the diameter of the air stream, and those are the lengths tabulated. On the other hand, when a cylinder in a tunnel stands on a large platform, the data are applicable to a cylinder without a platform and of twice the actual length-diameter ratio. Consequently, the tabulated values of that ratio for serials 36 to 43 , inclusive, are twice the actual. 


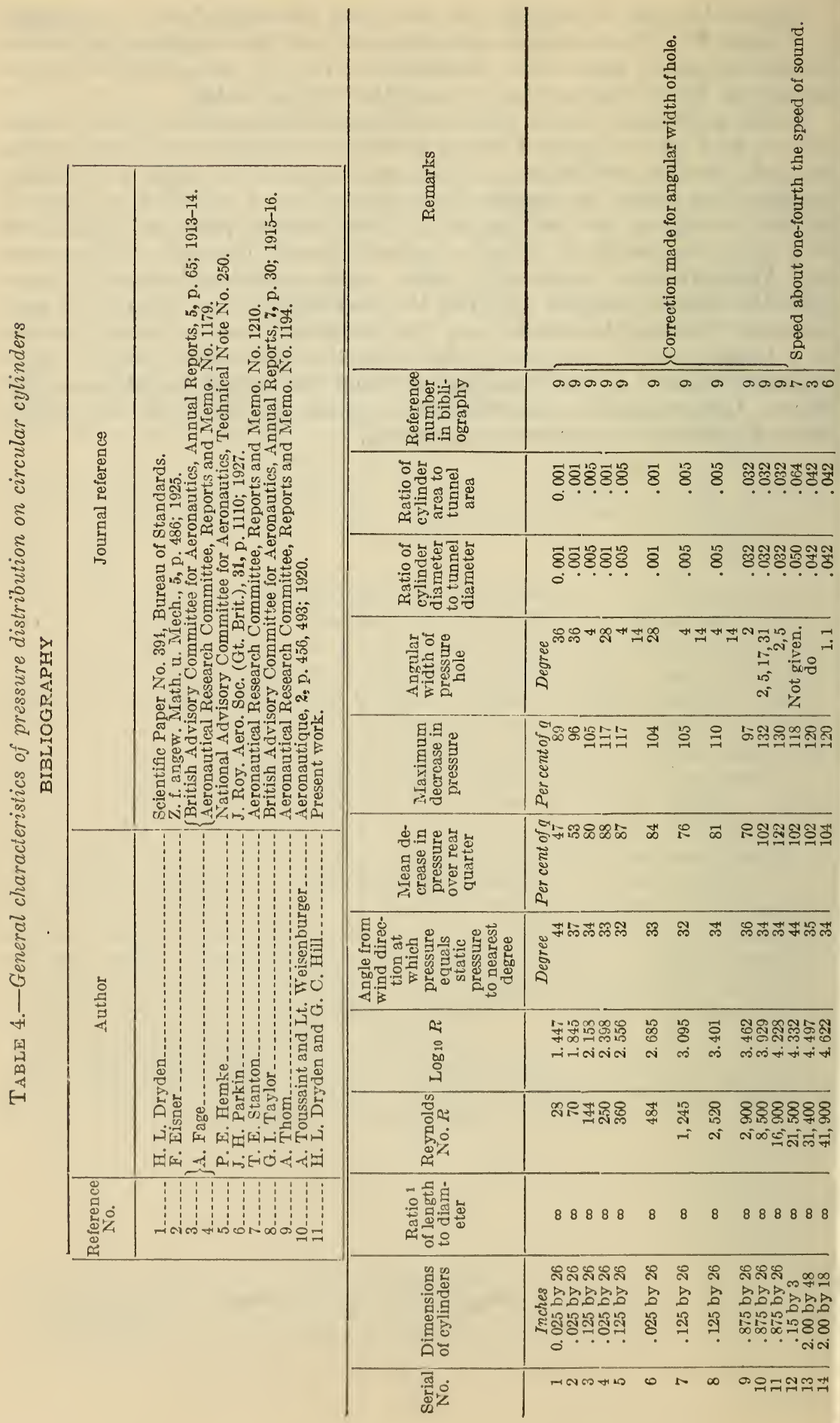




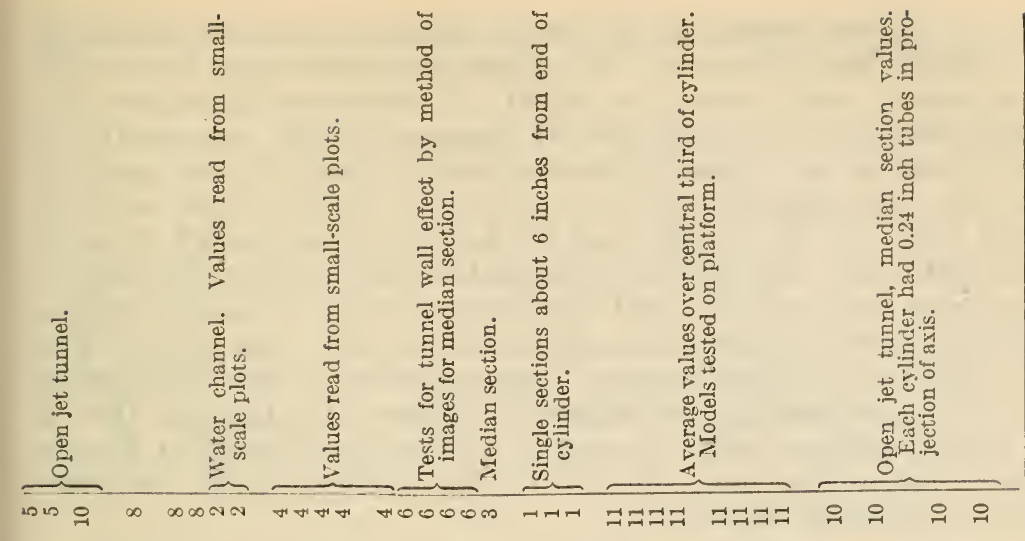

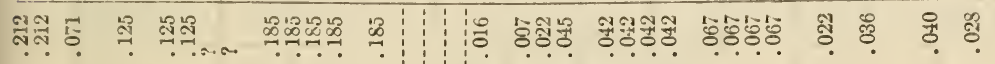

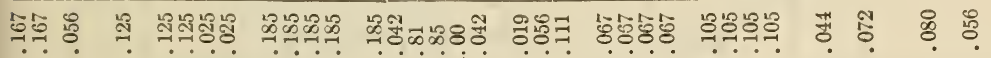

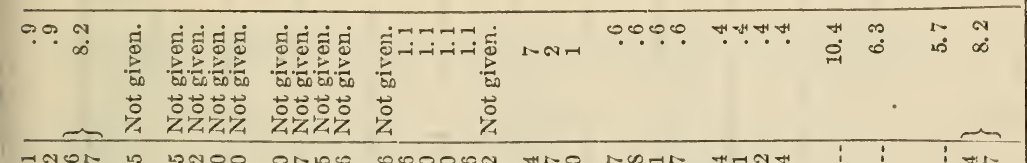

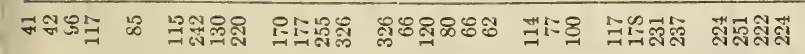

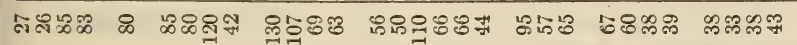
$\underbrace{\underbrace{1}}$

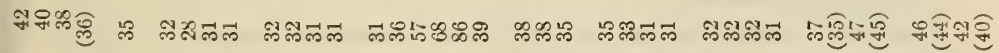

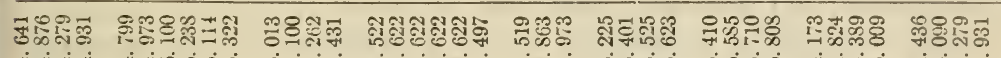
अंभi

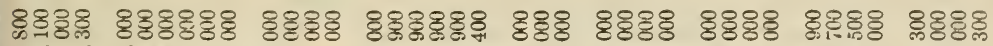

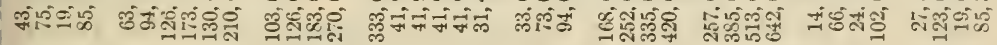

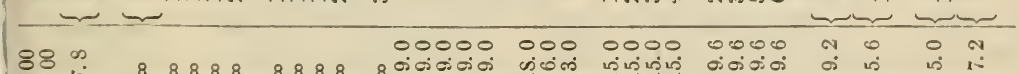

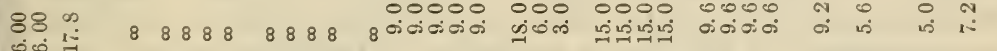
00 की

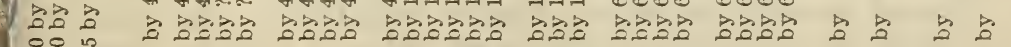

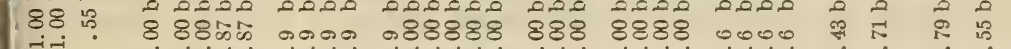

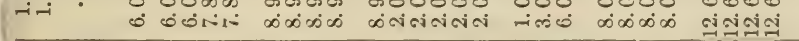

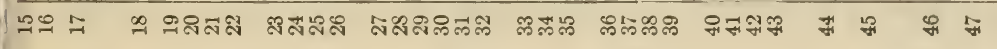


Of the 47 observations, 12 are to be discarded for the following reasons: Serial No. 12 because the speed was about one-fourth the speed of sound, and hence an effect of compressibility may be expected; serial Nos. 29, 30, and 31 because of the large ratio of cylinder diameter to tunnel diameter; serial Nos. 33, 34, and 35 because the measurements were not made at the median section; and serial Nos. 15, 16, 45, 46, and 47 because of the small ratio of length to diameter. For all the undiscarded observations the lengthdiameter ratio is at least 9 , and the three selected ${ }^{23}$ characteristics of the distribution of pressure vary but little with that ratio. The relation between the three general characteristics of the distribution and the Reynolds number are shown in Figures 13, 14, and 15. A certain correspondence with the curve of drag coefficient in Figure 1 may be noted in the curve (fig. 13) for the angle at which the pressure equals the static pressure.

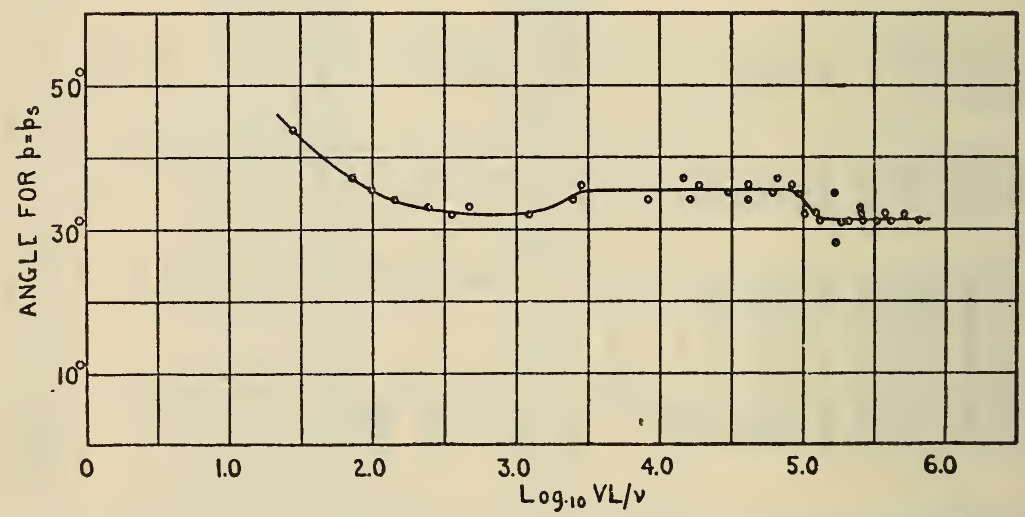

FIGURE 13.-Effect of Reynolds number upon the angle at which the pressure on an infinite cylinder is equal to the static pressure

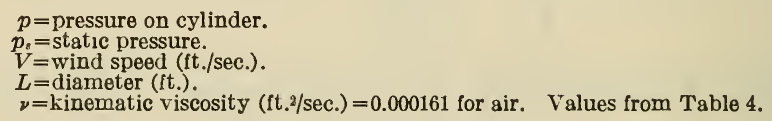

A comparison of our results with the results of Fage and Taylor shows that the critical flow was obtained at lower Reynolds numbers in the British tunnel, a difference to be attributed to the greater turbulence of the British wind tunnel. Taylor's value (serial 20) for the angle at which the pressure equals the static pressure is $28^{\circ}$ as compared with our value of $31^{\circ}$ (serial 43). We do not know whether this is to be attributed to the effect of length-diameter ratio or to the effect of the ratio of cylinder diameter to tunnel diameter. Fage (serials 13 and 32 ) found a value of $35^{\circ}$ for a cylinder of infinite length as compared to $39^{\circ}$ for a cylinder of length-diameter ratio equal to 9 at a Reynolds number of 31,400 .

Similar results hold for the mean decrease in pressure behind the cylinder. Above the critical region, Taylor finds 0.8 for the cylinder of infinite length as compared to our mean value of 0.38 for shorter

${ }_{23}$ The force coefficient varies very rapidly wilh length-diameter ratio. See Wieselsberger, Physikalische Zeitschrift, 23, p. 219; 1922. 
cylinders. Below the critical region, Fage finds 1.02 for the cylinder of infinite length as compared to 0.44 for a cylinder of length-diameter ratio of 9.

There are, however, certain discrepancies, as, for example (serials 13 and 18), between the results of Taylor and Fage at Reynolds

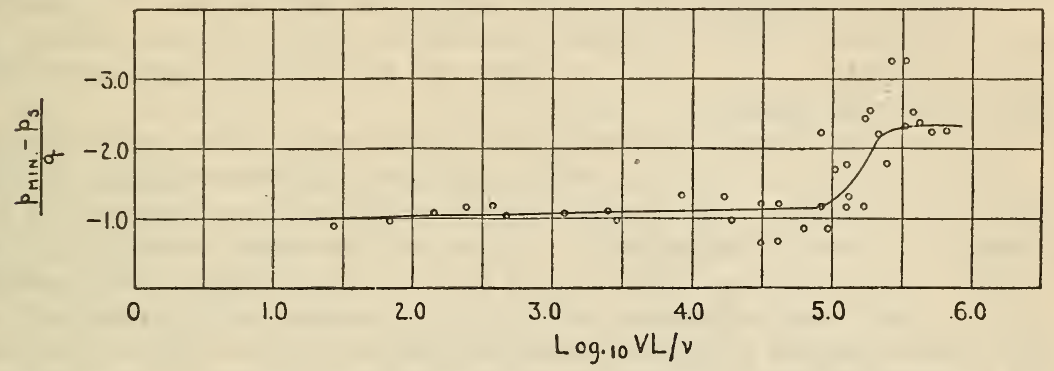

Figure 14.-Effect of Reynolds numoer upon the minimum absolute pressure on an infinite cylinder

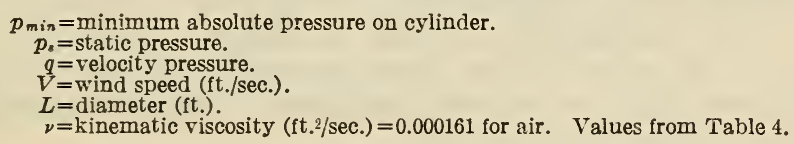

numbers below the critical region, which are probably ascribable to the effect of the ratio of cylinder diameter to tunnel diameter. Moreover, the good agreement between our own results for cylinders of different length-diameter ratios is perhaps a coincidence, the effect of the reduced length-diameter ratio balancing that of the increased ratio of cylinder diameter to tunnel diameter. Due caution must be exercised in applying these results to cylinders of other lengthdiameter ratios.

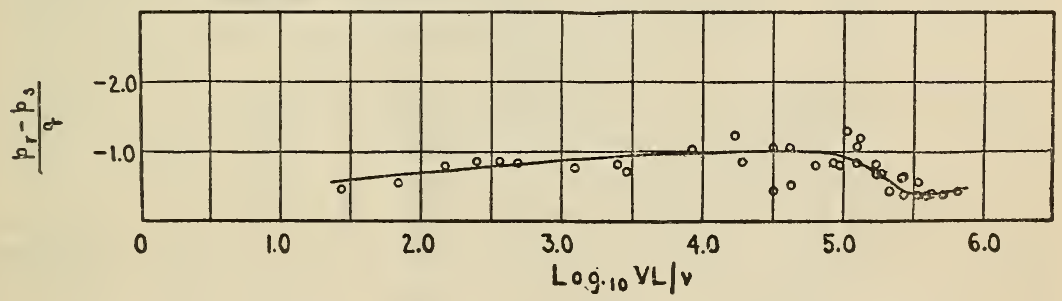

FIGURE 15.-Effect of Reynolds number upon the mean pressure on the rear of an infinite cylinder

$p_{r}=$ mean pressure on the rear.

$p_{s}=$ static pressure.

$q=$ velocity pressure.

$V=$ wind speed (ft./sec.).

$L=$ diameter (ft.).

$\nu=$ kinematic viscosity $\left(\mathrm{ft} .{ }^{2} / \mathrm{sec}\right.$.) $=0.000161$ for air. Values from Table 4 .

It is to be regretted that more information is not available on the effect of length-diameter ratio, especially above the critical region. At Reynolds numbers below the critical, increasing the lengthdiameter ratio decreases the zonal angle at which the pressure equals the static pressure and also decreases the absolute pressure on the rear of the cylinder. Figure 16 shows the best information avail- 
able regarding the effect of the length-diameter ratio on the zonal angle at which the pressure equals the static pressure. The data apply to the central part of the cylinder and for Reynolds numbers below the critical. As previously stated, serials 15,16 , and 17 are interpreted as applying to a cylinder whose length is the diameter of the air stream although the cylinders actually span the open-jet air stream, and serial 36 is interpreted as applying to a cylinder of length-diameter ratio equal to twice the actual ratio because of the presence of the platform.

With regard to the distribution along the length, the results shown in Figures 9 and 10 can be condensed into the form of Table 5 . In Table 5 the mean $C^{\prime}{ }_{D}$ at any section is given as a fraction of the average $C_{D}$ for the cylinder as a whole or, in other words, the local loading is expressed as a fraction of the average loading. The second column gives the values for a Reynolds number of 168,000 and the third for Reynolds numbers from 335,000 to 642,000 . It is seen that the loading is less uniform above the critical region. The greater drag associated with the end loss may be noted.

In most practical applications, the total overturning moment is desired. The distributions shown in Table 5 each give an overturning moment only 1.7 per cent greater than that for a uniform distribution so that the exact distribution along the length need not ordinarily be taken into account.

TABLE 5.-Distribution of pressure along length

\begin{tabular}{|c|c|c|}
\hline $\begin{array}{l}\text { Height of section above plat- } \\
\text { form, expressed as a per- } \\
\text { centage of the total length } \\
\text { of the cylinder }\end{array}$ & $\begin{array}{l}\text { A verage } C_{D}{ }^{\prime} \text { at } \\
\text { section for } \\
\text { Reynolds } \\
\text { number of } \\
168,000, \text { ex- } \\
\text { expressed as } \\
\text { fraction of } \\
\text { average } C_{D} \\
\text { for cylinder }\end{array}$ & $\begin{array}{c}\text { A verage } C_{D^{\prime}} \text { at } \\
\text { section for } \\
\text { Reynolds } \\
\text { numbers } \\
335,000 \text { to } \\
642,000 \text {, ex- } \\
\text { pressed as } \\
\text { fraction of } \\
\text { average } C_{D} \text { for } \\
\text { cylinder }\end{array}$ \\
\hline 99 & $\begin{array}{l}0.96 \\
1.12 \\
1.11 \\
1.07\end{array}$ & $\begin{array}{l}1.14 \\
1.33 \\
1.27 \\
1.04\end{array}$ \\
\hline $\begin{array}{l}70 \\
60 \\
40\end{array}$ & $\begin{array}{r}1.01 \\
.94 \\
.94 \\
.96\end{array}$ & $\begin{array}{l}.84 \\
.84 \\
.84 \\
.91\end{array}$ \\
\hline $\begin{array}{l}30 \\
20- \\
10\end{array}$ & $\begin{array}{r}.98 \\
.98 \\
.98 \\
.98\end{array}$ & $\begin{array}{l}1.00 \\
1.04 \\
1.04 \\
1.00\end{array}$ \\
\hline
\end{tabular}

Figure 11, showing the coefficients for the entire cylinder, indicates a difference in turbulence in the several wind tunnels. Taylor's pressure distribution curves indicate a drop at least as early as do Eiffel's.

In the Göttingen results and in ours the force and pressure distribution, respectively, are still changing at the highest Reynolds number. The Reynolds number corresponding to a chimney 20 feet in diameter in a wind of 100 miles per hour is 9,250,000. Extrapolation to such a value can not safely be made from model experiments limited to 642,000 . 


\section{SUMMARY OF MODEL EXPERIMENTS}

Measurements have been made of the pressure distribution over cylinders in and above the critical region of Reynolds number. The cylinders were mounted on a platform to simulate chimneys standing on the ground. The measurements show that the changes in the pressure distribution occurring at the critical region are as follows:

1. The zonal angle at which the pressure equals the static pressure decreases from $35^{\circ}$ to $31^{\circ}$.

2. The maximum value of the decrease in pressure below the static pressure is doubled, changing from 1.2 times the velocity pressure to 2.4 times the velocity pressure.

3. The mean value of the decrease in pressure over the rear quarter of the cylinder decreases from 0.7 of the velocity pressure to 0.4 of the velocity pressure.

4. The resultant force coefficient decreases to about 0.37 .

5 . The character of the distribution along the length is such as to give an overturning moment which is about 1.7 per cent greater than that obtained on the assumption of a uniform distribution.

At the highest Reynolds number used in these experiments, the distribution is still changing with the Reynolds number, so that application can safely be made only to small stacks or other cylindrical structures having diameters not significantly exceeding 1 foot.

\section{EXPERIMENTS IN NATURAL WINDS}

\section{THE INTERPRETATION OF EXPERIMENTS IN NATURAL WINDS}

Because the coefficients for cylinders were still changing at the maximum Reynolds numbers attainable in the wind tunnel, attention was given to experiments on large structures in natural winds. Such measurements have a somewhat greater appeal to the engineer than model experiments, although the difficulties of obtaining even reasonably accurate results are very great and the interpretation of observations is a very troublesome matter. The reason for the difficulty is the exceedingly large variability of the wind in intensity and direction. In wind tunnel experiments it is comparatively simple to install a Pitot-static tube and a static plate sufficiently far upstream to be unaffected by the presence or absence of the model. The tube can than be used to give a reference speed and the plate to give a reference pressure. With the model out we can measure the speed and the difference between the static pressure at the place to be occupied by the model and the reference pressure for known values of the reference speed. When the model is put into place we can be reasonably sure of the speed of the wind which strikes it, and of the static pressure at the model, the only error introduced being that due to the finite size of the air stream, which can be minimized by restricting the model area to a small percentage of the tunnel area.

How different is the situation in a natural wind. We can not remove the chimney at will, nor can we control the speed of the wind. If we locate a wind-measuring instrument far away from the chimney, there will be no definite relation between the force on the chimney and the measured wind speed. If we locate the instrument near the chimney, its readings will be affected by the presence of the chimney. 
There is no steady reference pressure. The absolute pressure inside a room in a building as well as in the outside air varies with the wind speed.

It occurred to one of us that it would be possible to secure the wind speed from the pressure measurements, if we could find some way of estimating the static pressure. If, for example, we may take the wind tunnel data of Figure 16 as indicating that the pressure equals the static pressure at a zonal angle of $35^{\circ}$, then the velocity pressure will be equal to the difference between the maximum pressure and the pressure where the angular width of the diagram is $70^{\circ}$, and from that the wind speed may be found by the aid of Table 2. An error of $1^{\circ}$ in the zonal angle ( $2^{\circ}$ in the width) corresponds to 5 per cent in the velocity head or to $2 \frac{1 / 2}{2}$ per cent in the speed. If the angle could be determined within $2^{\circ}$, the force coefficient would be known to within 10 per cent. Since the change in the angle occurring at the critical

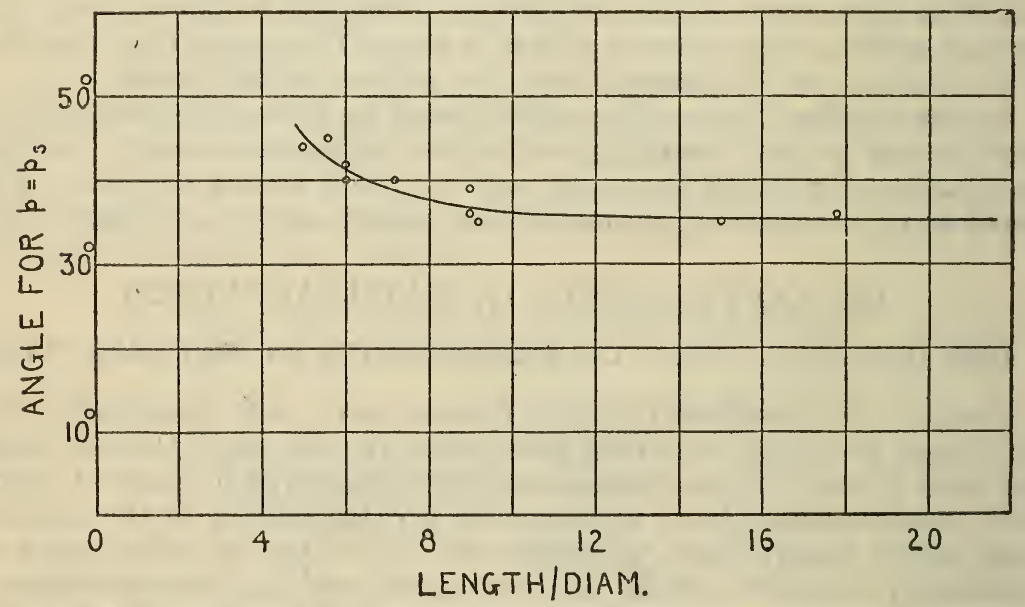

FIgUre 16.-Angle at which the pressure on cylinders of various lengthdiameter ratios is equal to the static pressure: Reynolds numbers below the critical

$p=$ pressure on cylinder.

$p_{s}=$ static pressure.

region is only $4^{\circ}$ and the total change between a length-diameter ratio of 9 and infinity is only $4^{\circ}$, it appears that there is some hope of fixing the angle within $2^{\circ}$.

This method of attack has the advantage of securing a value of the speed of the wind striking the chimney at the level where the measurements are made. It also happens, as will be explained later, that the force coefficient can be obtained from a pressure distribution curve plotted to an arbitrary scale and with an arbitrary reference pressure. The method has the disadvantage that the results of the measurements on the large structure do not stand alone but are interpreted on the basis of a particular kind of extrapolation of data for models, an extrapolation which is, however, far safer than a direct extrapolation of force measurements.

We wish again to point out that this method of treatment of the wind-pressure observations implies the division of the wind-pressure 
B. S. Journal of Research, RP221

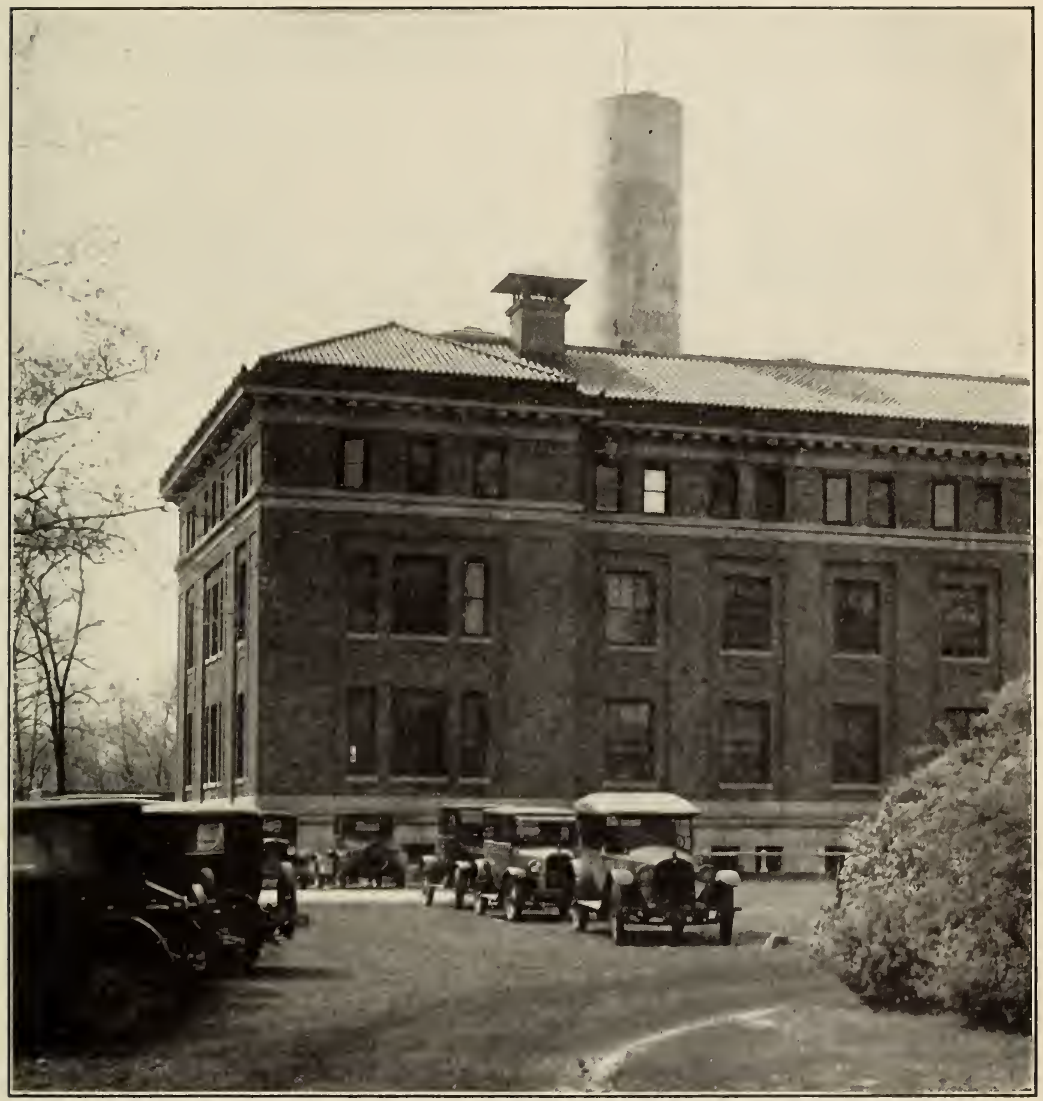

Figure 17.-The $10 \times 30$ foot experimental stack 
problem as outlined in the introductory section. If it were possible to maintain a continuous record of the pressure on the chimney over a period of several years, a statistical study of the correlation between maximum wind forces and the records of the Weather Bureau station several miles away would seem to give at once the information desired by the engineer. However, the relative exposures of the chimney and the Weather Bureau station would affect the results, and the occurrence of local storms at the two places at different times would so distort the small probabilities, which are of greatest interest, that any general application of the results would be impossible. The analysis suggested in this paper represents an attempt to separate out the effect of the shape of the object from that of the speed of the wind. The object of our observations in natural winds was the determination of force coefficients only, not that of the frequency of occurrence of high winds nor of the relation between mean speed and gust speed.

\section{EXPERIMENTS ON A CYLINDRICAL STACK, 10 FEE'T IN DIAIIETER AND 30 FEET HIGH}

(a) DISTRIBUTION OF PRESSURE, STACK 10 FEET IN DIAMETER AND 30 FEET HIGI

As the Bureau of Standards was to erect a new power plant chimney on which a more or less permanent installation could be made, it was considered advisable to try the new method on a somewhat smaller scale and under conditions such that the natural wind measurements could be made to stand alone. For this purpose an experimental stack 10 feet in diameter and 30 feet high was erected on the roof of the West Building of the Bureau of Standards. (Fig. 17.) The stack was constructed of a comparatively light timber framework consisting of rings, separated by compression members, to which a sheet metal covering was nailed. The structure was located over a skylight opening, and guy wires were carried inside the structure to the roof beams of the building. At an elevation of about 20 feet above the roof, 24 pressure holes were spaced equally around the circumference. From each hole a separate pipe (three-eighths-inch diameter) was led down the interior of the stack to the observation room in the attic of the building. As first installed, each pressure hole was formed by extending the pipe itself through the sheet metal by a distance of about one-sixteenth-inch and holding the pipe in position by lock washers. It was found that the presence of these small projections produced large suction effects and consequent errors. Wind-tunnel tests showed that the size of the opening (within the limits used) had no large effect. Depression of the hole below the surface gave only small effects, but any projection gave large errors. The pressure holes were then reconstructed by soldering a tube on the inside of the sheet metal covering and drilling from the outside into the tube with a one-thirty second-inch drill. All burrs around the hole were carefully removed.

The 24 pipes were brought together at the observing station with a valve in each line so arranged that all 24 valves could be opened or closed simultaneously by a common operating lever. The valves were of the plug type so that no volume changes occurred on closing them. Each line after passing through its valve led to one tube of a multiple manometer similar to the one which was used for the windtunnel tests and which was described in Scientific Paper No. 523. 
The other side of the manometer was left open to the air in the observation room. An installation similar to the one used for the experimental stack is shown in Figure 24.

About 10 feet above the top of the stack on the west side a Pitotstatic tube was mounted on a wind vane. A sketch of the tube is

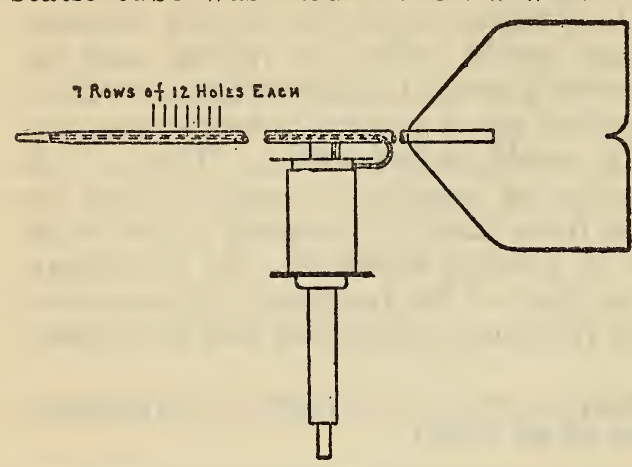
shown in Figure 18. The pressures from the Pitot and static tubes were led through oil seals to pipes running down to the observation room. The differences between the Pitot and static pressures and the pressure in the observation room were measured on the manometer used to determine the pressure distribution, replacing two stations on the lee side of the stack where the pressure is nearly the same for a

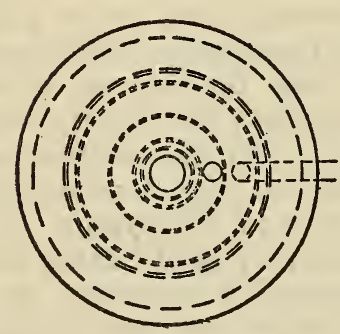
number of stations.

The experimental procedure was as follows: On a day when the wind reached speeds greater than 25 miles per hour, the valves were opened and the observer, watching the fluctuations, closed the valves when the wind speed was reasonably high and steady. Attention was directed to securing the

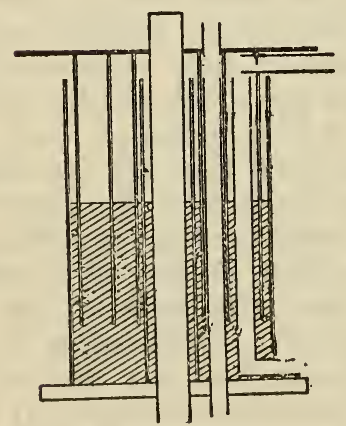

Figure 18. - Sketch of Pitot-static tube and oil seal used with weather vane for measurements of wind speed

best approximation to steady conditions. The readings of the 24 tubes were then recorded. The valves were again opened and the process repeated some 10 or 12 times.

A typical set of observations is shown in Table 6 , in the first two columns.

The observed gauge readings are multiplied by the slope of the manometer (0.196), by the density of the kerosene $(0.820)$, and by a conversion factor $(2.045)$ to obtain the pressure differences in lbs./ft. ${ }^{2}$ These pressure differences are the pressures at the several holes, measured from room pressure as base. From a plot (not shown) of several points near the maximum, the value of the maximum pressure is estimated as well as the angular position at which the maximum occurs. The value of the maximum pressure is then subtracted from all read- 
ings, giving the amounts by which the pressures at the holes exceed the maximum pressure. ${ }^{24}$ The value of the mean excess pressure at the rear is then computed, and the ratios to it of the excess pressure at each of the several holes is calculated. These ratios are given in the last column of the table, and in Figure 19 they are plotted with reference to the angle as measured from the estimated position of maximum pressure. Curves of this nature may be used to study the similarity of distributions at several speeds and for different cylinders. As the ordinates of the curve are ratios of pressure differences, the curve is entirely independent of the unit in terms of which the pressures are expressed-it is not necessary that they be expressed in lbs./ft. ${ }^{2}$

\section{TABLE 6.-Typical observation on experimental stack}

[January 29, 1929 No. 2, Run 1]

\begin{tabular}{|c|c|c|c|c|}
\hline $\begin{array}{l}\text { Designation of hole ( } 1 \text { is approximately north). } \\
\text { Numbers run from north to east to south to } \\
\text { west }\end{array}$ & $\begin{array}{l}\text { Observed net } \\
\text { gauge reading }\end{array}$ & $\begin{array}{l}\text { Pressure dif- } \\
\text { ference with } \\
\text { room as base } \\
\text { pressure }\end{array}$ & $\begin{array}{l}\text { Pressure dif- } \\
\text { ference with } \\
\text { maximum } \\
\text { pressure as } \\
\text { base pressure }\end{array}$ & $\begin{array}{l}\text { Ratio of pres- } \\
\text { sure at hole to } \\
\text { mean pres- } \\
\text { sure on the } \\
\text { rear. Base } \\
\text { pressure is } \\
\text { maximum } \\
\text { pressure }\end{array}$ \\
\hline 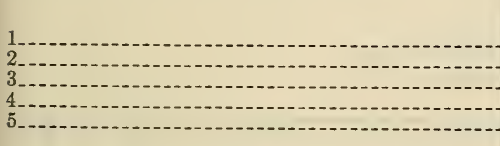 & $\begin{array}{r}-13.2 \\
-12.1 \\
-3.3 \\
-1.7 \\
-2.7\end{array}$ & $\begin{array}{r}\text { Lbs./ft. }{ }^{2} \\
-4.34 \\
-3.98 \\
-1.08 \\
-.56 \\
-.89\end{array}$ & $\begin{array}{r}\text { Lbs./ft. }{ }^{2} \\
-7.81 \\
-7.45 \\
-4.55 \\
-4.03 \\
-4.36\end{array}$ & $\begin{array}{l}1.83 \\
1.75 \\
1.07 \\
.95 \\
1.02\end{array}$ \\
\hline 8, Pitot tube_ & $\begin{array}{r}-2.0 \\
-.5 \\
9.3 \\
-2.3\end{array}$ & $\begin{array}{r}-.66 \\
-.16 \\
3.05 \\
-.76\end{array}$ & 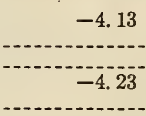 & .97 \\
\hline 1113 & $\begin{array}{r}-2.8 \\
-2.5 \\
-2.8 \\
-4.3\end{array}$ & $\begin{array}{r}-.92 \\
-.82 \\
-.92 \\
-1.41\end{array}$ & $\begin{array}{l}-4.39 \\
-4.29 \\
-4.39 \\
-4.88\end{array}$ & $\begin{array}{l}1.03 \\
1.01 \\
1.03 \\
1.15\end{array}$ \\
\hline 1616 & $\begin{array}{r}-12.3 \\
-9.1 \\
-2.4 \\
5.1 \\
9.5\end{array}$ & $\begin{array}{r}-4.04 \\
-2.99 \\
-.79 \\
1.68 \\
3.12\end{array}$ & $\begin{array}{l}-7.51 \\
-6.46 \\
-4.26 \\
-1.79 \\
-.35\end{array}$ & $\begin{array}{r}1.76 \\
1.52 \\
1.00 \\
.42 \\
.08\end{array}$ \\
\hline $\begin{array}{l}21 \\
22 \\
23 \\
24\end{array}$ & $\begin{array}{r}9.8 \\
5.6 \\
-1.2 \\
-8.8\end{array}$ & $\begin{array}{r}3.22 \\
1.84 \\
-.39 \\
-2.89\end{array}$ & $\begin{array}{l}-.25 \\
-1.63 \\
-3.86 \\
-6.36\end{array}$ & $\begin{array}{r}.06 \\
.38 \\
.91 \\
1.49\end{array}$ \\
\hline
\end{tabular}

1 Tube leaking badly; readings discarded.

Estimated maximum pressure, $3.47 \mathrm{lbs}$./ft. ${ }^{2}$ at $9^{\circ}$ north of hole 20.

Mean pressure on rear (maximum pressure as base), $-4.26 \mathrm{lbs} . / \mathrm{ft} .{ }^{2}=1.17$ times velocity pressure from distribution.

Velocity pressure from Pitot, $3.21 \mathrm{lbs} . / \mathrm{ft} .^{2}$ (35.4 miles per hour).

Velocity pressure from distribution, using static from tube, $-3.63 \mathrm{lbs} . / \mathrm{ft} .{ }^{2}$ ( 37.6 miles per hour).

Angular separation of points at which the pressure equals static of tube, $69^{\circ}$.

The curve of Figure 19 represents the distribution of pressure around the cylinder, with the maximum pressure, $p_{\max }$, as the reference pressure and the difference between the maximum pressure $p_{\max }$ and the pressure on the rear $p_{r}$ as the unit of pressure. The next step is to determine the average force per unit length exerted

${ }^{24}$ The absolute pressure at the holes is less than the maximum pressure. The "excess pressure." therefore, has a negative sign as shown in the fourth column of Table 6. 
upon this section of the cylinder and in a direction parallel to the wind, namely

$$
\int \frac{p-p_{\max }}{p_{\tau}-p_{\max }} \sin \Theta d s=\int \frac{p_{\max }-p}{p_{\max }-p_{\tau}} d w
$$

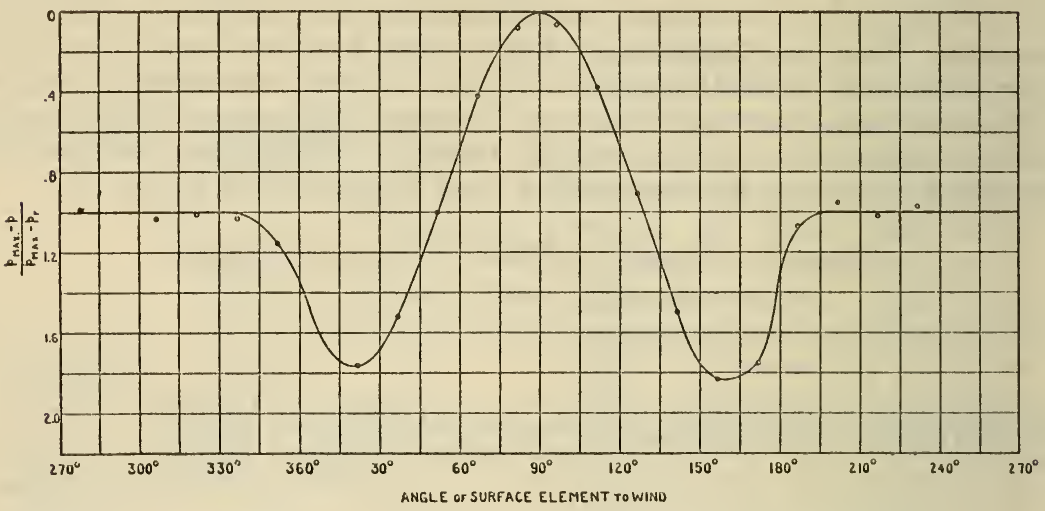

FIgURE 19.-Pressure distribution on experimental stack, sample run of Table 6

$p=$ pressure at station.

$p_{\max }=$ maximum absolute pressure on stack. $p_{r}=$ mean pressure on rear quarter.

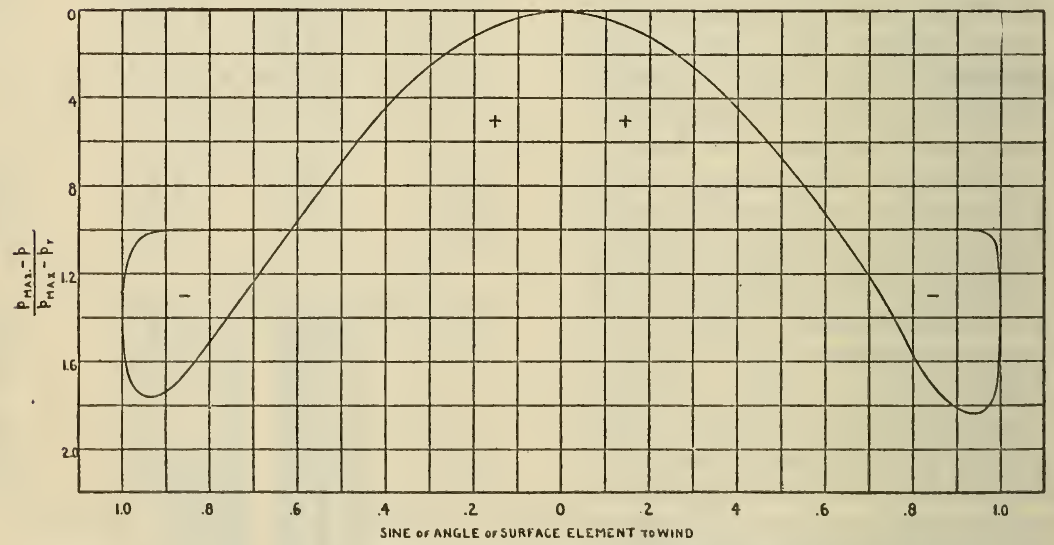

Figure 20.-Plot for use in integrating the pressure distribution of Figure 19 so as to get the resultant mean pressure at section

\footnotetext{
$p=$ pressure at station.

$p_{\max }=$ maximum absolute pressure on stack.

$p_{r}=$ mean pressure ou rear quarter.
}

where $\theta$ is the angle of the surface element to the wind, $d s$ is an element of the circumference and $d w$ is an element of the projection of the surface element on a plane normal to the wind; $\sin \theta d s=d w$, and it is obvious that

$$
\frac{p-p_{\max }}{p_{r}-p_{\max }}=\frac{p_{\max }-p}{p_{\max }-p_{r}}
$$

The integration may be performed graphically with the aid of Figure 20. Dividing the integral by the diameter $(w)$ of the cylinder, the 
average wind force per unit area at this section is obtained in terms of $p_{\max }-p_{\tau}$ as unit. For the example used, a value of 0.22 is obtained.

Attention is again called to the fact that this value is arrived at, or can be arrived at, from a plot of the pressure distribution on any arbitrary scale and with any arbitrary reference pressure to begin with; that is, from readings on a manometer of any slope (so long as all tubes have the same slope) and with its reservoir connected to any reference pressure. If, as in the experiments described, the velocity pressure is measured on the same manometer, we inay determine at once the ratio of $p_{\max }-p_{\tau}$ to the velocity pressure (1.17 in the example) and hence obtain the true force coefficient $(1.17 \times 0.22$ $=0.26$ ) without any knowledge of the slope of the manometer. Or, if from Table 4 we estimate the probable value of the zonal angle at which the pressure is equal to the static pressure as $31^{\circ}$ for a cylinder of infinite length at Preynolds numbers above the critical region, and if we estimate from Figure 16 that the correction to a length-diametor ratio of 6 is $6^{\circ}$, obtaining a probable value of $37^{\circ}$, we may proceed as follows. From the estimated value of the zonal angle $\left(37^{\circ}\right)$ the angular width of the distribution curve at such an ordinate that the pressure equals the static pressure is estimated to be $74^{\circ}$. From Figure 19, this angular width corresponds to

$$
\frac{p_{\max }-p}{p_{\max }-p_{r}}=0.95
$$

But at this ordinate, $p=p_{s}$, and hence $p_{\max }-p=p_{\max }-p_{s}=$ the velocity pressure $q$. Thus $\frac{q}{p_{\max }-p_{r}}=0.95$ or $\frac{p_{\max }-p_{r}}{q}=1.05$ and the true shape coefficient is $1.05 \times 0.22=0.23$. This last procedure is illustrative only. We have so little information as to the effect of lengthdiameter ratio above the critical region that predictions for short cylinders are uncertain. Furthermore the experimental chimney 10 feet in diameter and 30 feet high is not mounted on an infinite plane but on top of a building and its effective length-diameter ratio is hard to determine. Actually the zonal angle obtained by use of the static tube readings is $34.5^{\circ}$ which corresponds to an effective length-diameter ratio of about $7 \frac{1}{2}$ using the procedure indicated above.

The method which has been outlined for reducing the observations may appear somewhat indirect and cumbersome. Its object is to postpone all uncertainties until the last step, namely, until the determination of the ratio $\left(p_{\max }-p_{\tau}\right) / q$ or its equivalent, the determination of the zonal angle at which the pressure equals the static pressure.

(b) OVERTURNING MOMENT, STACK 10 FEET IN DIAMETER AND 30 FEET HIGH

The measurement of the pressure distribution at a given elevation gives information as to the average wind load at that elevation only. It tells nothing about the actual overturning moment exerted by the wind. It seemed desirable to attempt to measure that directly. The method employed is indicated schematically in Figure 21. The stack was supported at four points at the corners of a square, the sides of which run north and south and east and west, and means were provided, as explained later, for measuring the reactions at the four 
points. When no wind is blowing, the reactions will be caused solely by the weight of the stack. When the wind blows, the reactions will

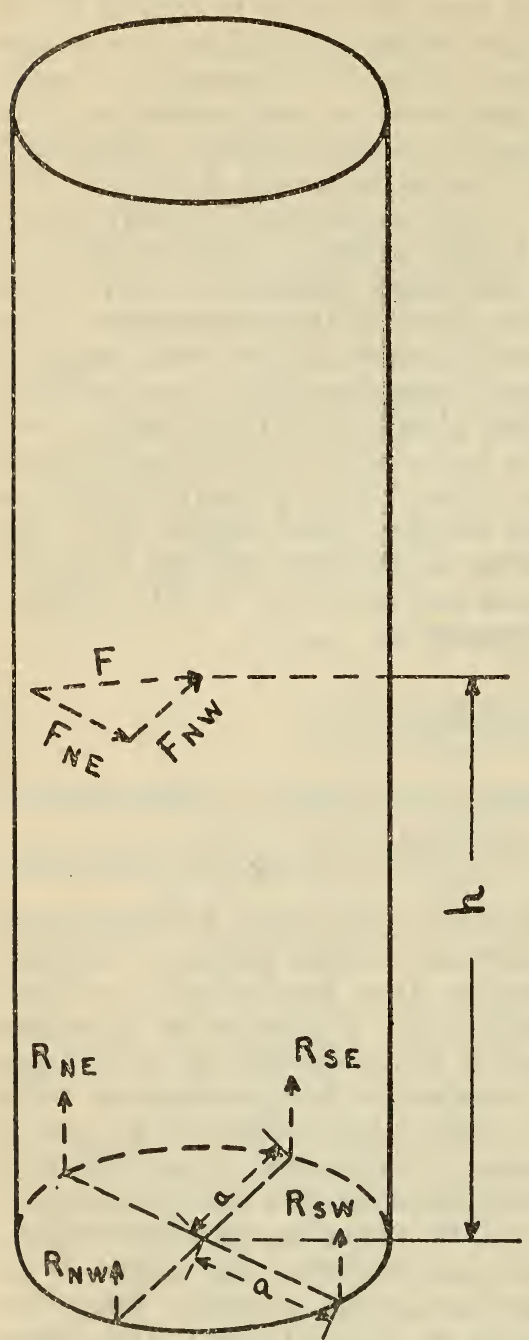

Figure 21.-Diagram illustrating how the wind force on the experimental stack was computed from the measured reactions at four points of support

$F=$ wind force.

$F_{N B}=$ component of $F$ ind force in $N E-S W$ direction.

$F_{N W}=$ component of wind force in $N W-S E$ direction.

$h=$ lieight of center of stack above the plane of the four supports.

$2 a=$ distance between $N E$ and $S W$ or $N W$ and $S E$ supports.

$R_{N E}=$ upward reaction on cylinder at $N E$ support.

$R_{S B}=$ reaction at $S E$ support.

$P_{S W}$ at $S W$ support, and $R_{N W}$ at $N W$ support. change. We shall assume that the effect of the wind in overturning the chimney is equivalent to the effect of a force $F$ acting at the center of the projected area of the chimney, which is at an elevation, $h$, above the plane containing the points of application of the reactions at the base. We shall call the increase in the reaction at the northwest corner, $R_{N W}$, the others, $R_{N E}, R_{S E}$, and $R_{S W}$ and shall regard them as positive when the upward reaction on the cylinder increases and hence the downward force on the measuring apparatus increases. The length of the diagonal of the square is called $2 a$. Resolving the wind force into components parallel to the diagonals of the base square as indicated in Figure 21, and taking moments about each of the diagonals in turn, we find.

$$
\begin{aligned}
& F_{N E} h=\left(R_{S W}-R_{N E}\right) a \\
& F_{N W} h=\left(R_{S E}-R_{N W}\right) a
\end{aligned}
$$

The total force, $F$, is given by

$$
F=\sqrt{F_{N W^{2}}+F_{N E^{2}}}
$$

and its azimuthal angle, $\alpha$, from the meridian

$$
\alpha=315^{\circ}+\tan ^{-1} \frac{F_{N E}}{F_{N W}^{\prime}}
$$

The force coefficient $C_{D}$ is given by

$$
C_{D}=\frac{F}{A q}
$$

where $A$ is the projected area of the stack $\left(300 \mathrm{ft}^{2}\right)$ and $q$ is the velocity pressure.

The reactions were measured by the use of pressure capsules of the sylphon type (metal bellows). The sylphons were connected to 
Bourdon tube pressure gauges by pipe lines, each system of sylphon, piping, and gauge being filled with kerosene. Each pressure gauge was calibrated by comparison with a mercury column, and each sylphon and gauge system was calibrated in a compression testing machine to determine the effective area of the sylphon. When installed under the stack, each pipe line contained a valve, and the four valves were connected to a common operating lever. 'This was spring operated, the trigger being released by the lever which operated the valves in the pipe lines for pressure-distribution measurements. Arrangements were provided for equalizing the pressures at any time and for refilling so as to replace any slight leakage at the valves.

The lateral force on the stack was taken by a system of tension wires approximately in the plane of the top of the sylphons. During measurements of the overturning moment, the guy wires were slackened. The stack was not originally designed to be supported at four points and the necessary inclusion of the points within the cylinder reduced the stabilizing moment of the weight of the stack. As a result of continued racking by the wind and the decreased resistance to overturning caused by the four-point support, the stack was blown from the roof on March 7, 1929, fortunatcly without serious damage to the building. The wind gusts at that time exceeded a true wind speed of 60 miles per hour.

Table 7 shows a typical group of readings and the method of reduction. The chief experimental difficulties were due to the inability of the observer to shut off the wind so as to obtain zero readings. The sylphons moved very little under different loads, and each could be made to take any fraction of the total load within wide limits by controlling the quantity of kerosene in the system. It was necessary therefore to equalize the pressures in the four sylphons, at a time when there was no wind, by the simple device of interconnecting them. The pressures could not be exactly equalized since the center of gravity of the stack was not exactly at the intersection of the diagonals of the square of the supporting sylphons.

\section{TABLE 7.-Typical set of observations on overturning moment}

[ $h=14.33$ feet, $a=3.98$ feet, effective area of sylphon $=97$ in. $\left.{ }^{2}\right]$

\begin{tabular}{|c|c|c|c|c|}
\hline Sylphon & NW & NE & $\mathrm{SE}$ & ST \\
\hline 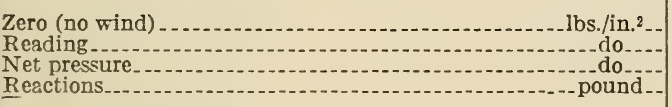 & $\begin{array}{r}13.6 \\
7.1 \\
-6.5 \\
-630\end{array}$ & $\begin{array}{r}12.8 \\
13.9 \\
1.1 \\
107\end{array}$ & $\begin{array}{r}14.9 \\
20.8 \\
5.9 \\
572\end{array}$ & $\begin{array}{r}15.0 \\
12.0 \\
-3.0 \\
-291\end{array}$ \\
\hline
\end{tabular}

\section{Hence}

$$
\begin{aligned}
& F_{N E}=\frac{(-291-107) 3.98}{14.33}=-111 \text { pounds } \\
& F_{N W}=\frac{(572+630) 3.98}{14.33}=334 \text { pounds } \\
& F=\sqrt{334^{2}+111^{2}}=353 \text { pounds }
\end{aligned}
$$


From Table 6, $q$ from distribution $=3.63 \mathrm{lbs} . / \mathrm{ft} .{ }^{2}$. Hence $C_{D}$ $=\frac{353}{3.63 \times 300}=0.32 . \quad \alpha=315^{\circ}+\tan ^{-1} \frac{-111}{334}=315^{\circ}-18^{\circ}=297^{\circ}$ as com -

pared with $289^{\circ}$ from the distribution. Owing to a small amount of leakage and to some creeping of the sylphons under load (the thin metal of the bellows was loaded somewhat above the elastic limit), the zero readings showed a certain amount of drift which could only be checked by observations when there was no wind. The errors introduced can not, in general, exceed 10 per cent and are probably of the order of 5 per cent.

(c) SUMMARY, STACK 10 FEET IN DIAMETER AND 30 FEET HIGH

Table 8 contains a summary of all observations of the overturning moment and the derived force coefficients, together with the data taken simultaneously on the pressure distribution. The table also contains the readings obtained from the Pitot-static tube. Throughout the table the static pressure is that obtained from the static connection of the Pitot-static tube. The velocity pressure used in the computation of force coefficients is that obtained from the maximum pressure on the cylinder and the static pressure from the Pitot-static tube. Column 8 of the table shows that the wind speed as obtained from the Pitot-static tube is on the average nearly the same as that obtained from the maximum pressure on the cylinder and the static pressure from the Pitot-static tube. 


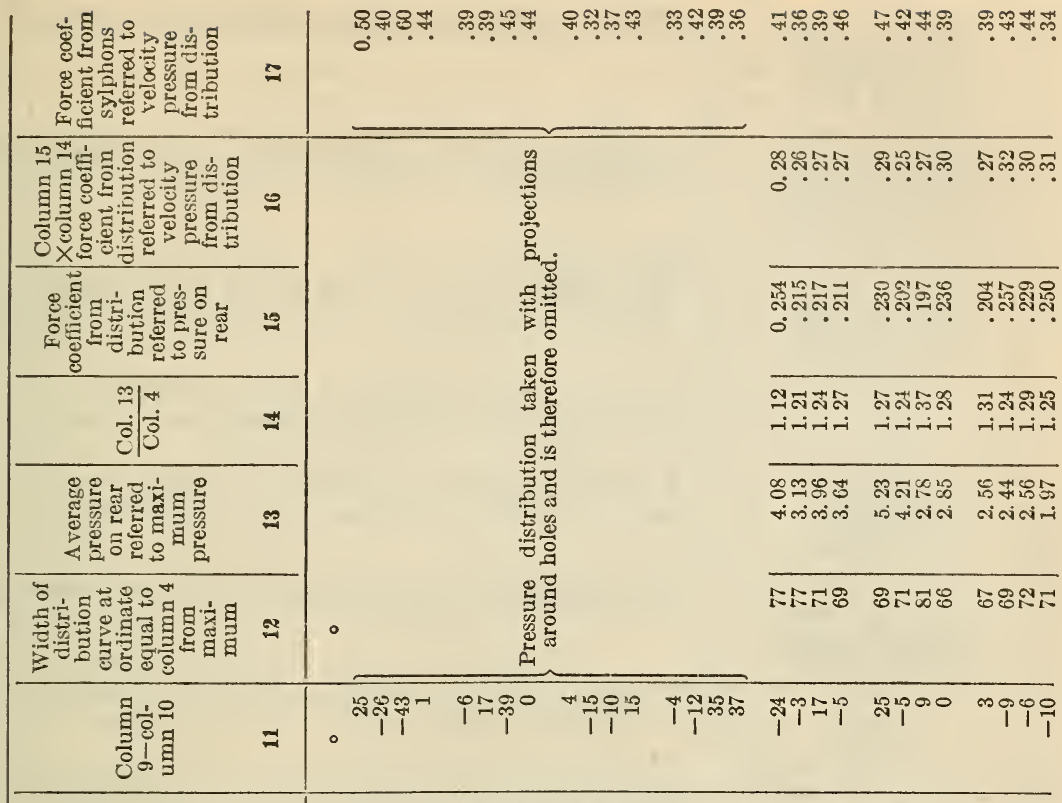

\begin{tabular}{|c|c|c|c|c|c|c|c|c|}
\hline 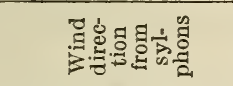 & 인 & 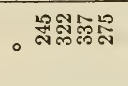 & 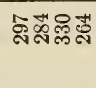 & 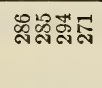 & 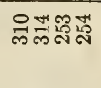 & స్లైస్టిర్లి & 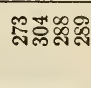 & 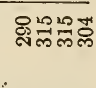 \\
\hline 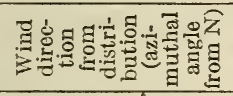 & $\theta$ & 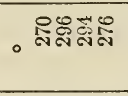 & స్టేర్లైస్టై & 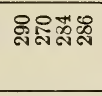 & 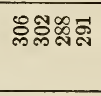 & ర్లిసేలిజి & 寻 & శ్సిర్లిం్లిష్లే \\
\hline 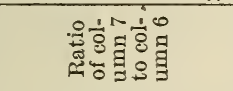 & $\infty$ & 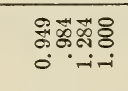 & 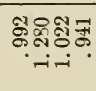 & है & 궁요유. & 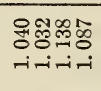 & 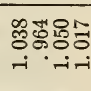 & 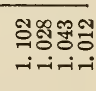 \\
\hline 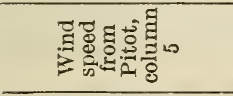 & - & 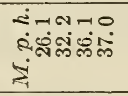 & 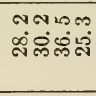 & 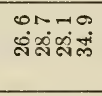 & एా & 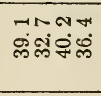 & 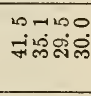 & 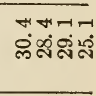 \\
\hline 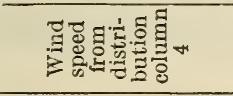 & 0 & 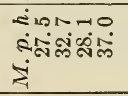 & 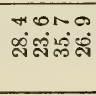 & 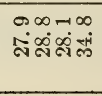 & $\begin{array}{l}1000 \pi \\
\infty \\
\infty \\
\infty\end{array}$ & 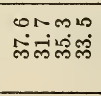 & 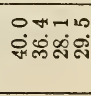 & $\begin{array}{l}0000 \\
\text { ลंजีลंजี }\end{array}$ \\
\hline 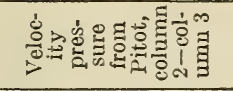 & مـ & 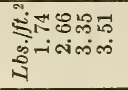 & 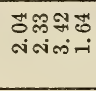 & 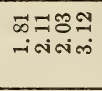 & $\begin{array}{l}\text { מRRg } \\
\text { miniNi }\end{array}$ & 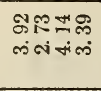 & 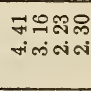 & 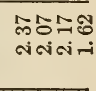 \\
\hline 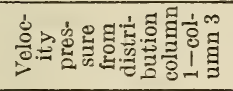 & + & 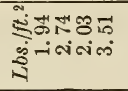 & 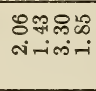 & 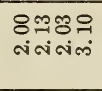 & 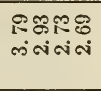 & 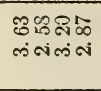 & $\begin{array}{l}\text { Z유: } \\
\text { मimai }\end{array}$ & 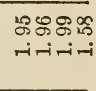 \\
\hline 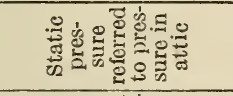 & $\infty$ & 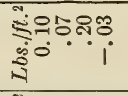 & 8888 & 8.రํ. & 동유. & : & ణొఃః? & 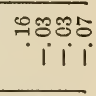 \\
\hline 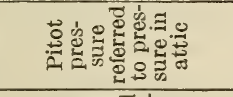 & Q & 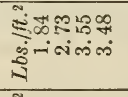 & 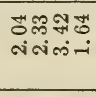 & 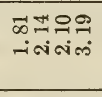 & 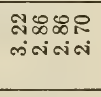 & 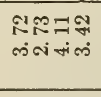 & 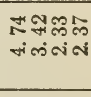 & 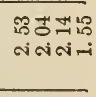 \\
\hline 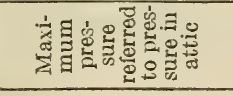 & -1 & 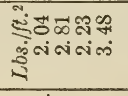 & 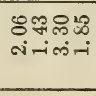 & 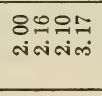 & 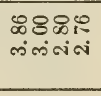 & 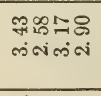 & 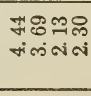 & 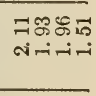 \\
\hline 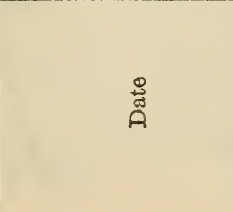 & & 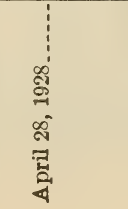 & & & & 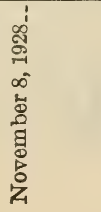 & & \\
\hline
\end{tabular}




\begin{tabular}{|c|c|c|c|}
\hline 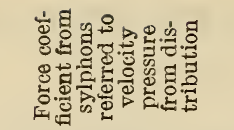 & $=$ & "... & H \\
\hline 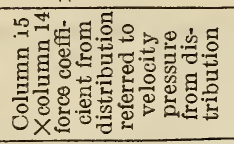 & 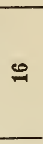 & 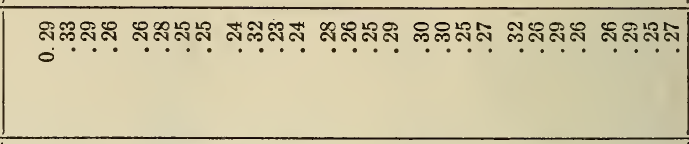 & 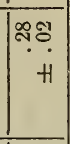 \\
\hline 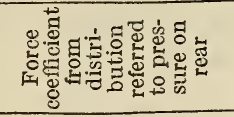 & 29 & 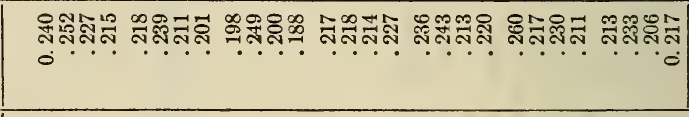 & 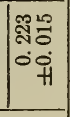 \\
\hline 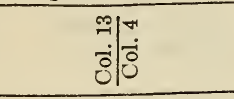 & $\Xi$ & 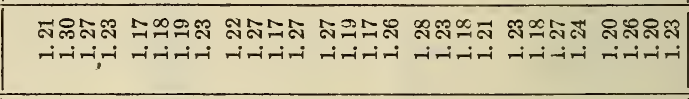 & 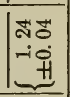 \\
\hline 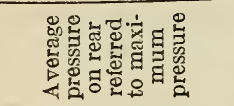 & $\approx$ & 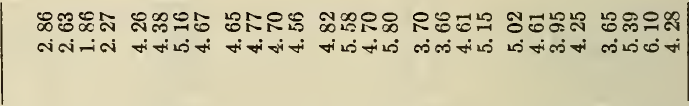 & \\
\hline 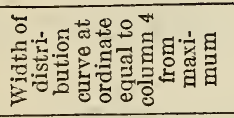 & $\approx$ & 。 & $\stackrel{+1}{\circ}$ \\
\hline 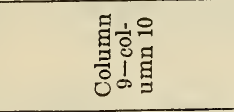 & $=$ & - & \\
\hline 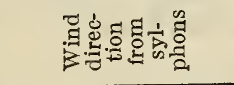 & 울 & 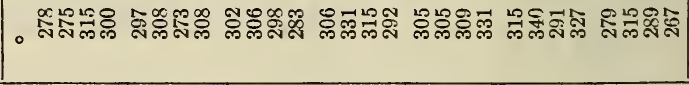 & \\
\hline 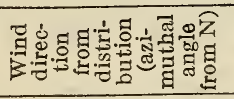 & o & 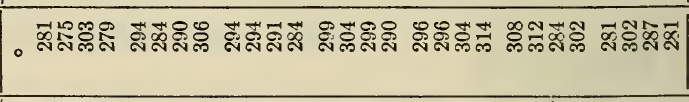 & \\
\hline 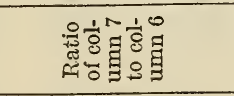 & $\infty$ & 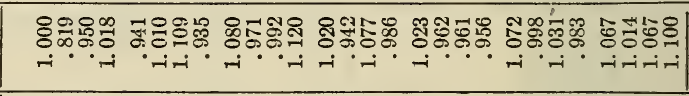 & 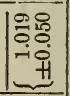 \\
\hline 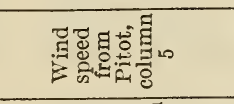 & - & 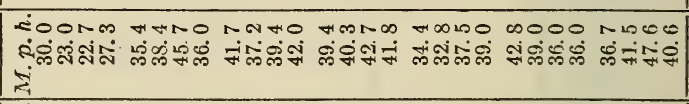 & \\
\hline 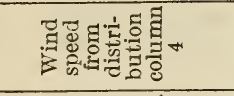 & $\infty$ & 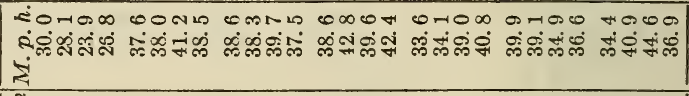 & \\
\hline 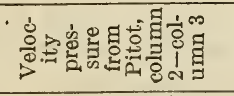 & $\infty$ & 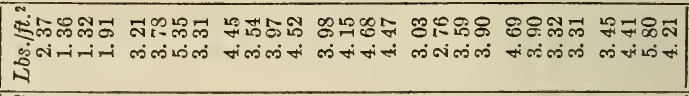 & \\
\hline 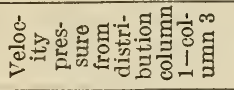 & 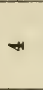 & 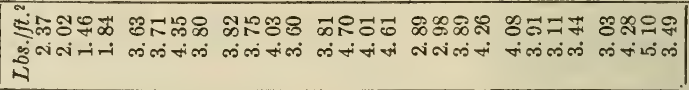 & \\
\hline 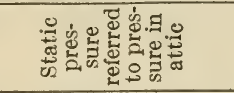 & $\infty$ & 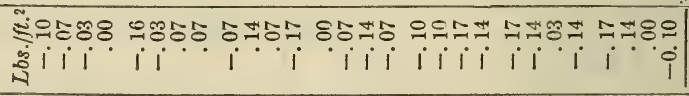 & \\
\hline 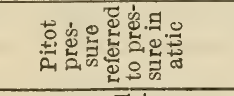 & $\propto$ & 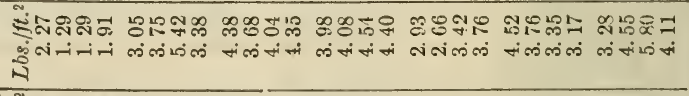 & 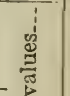 \\
\hline 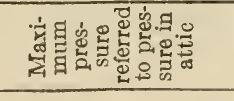 & - & 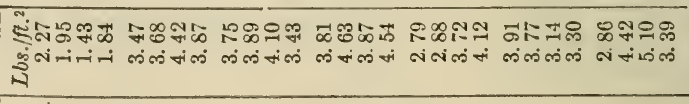 & 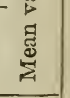 \\
\hline 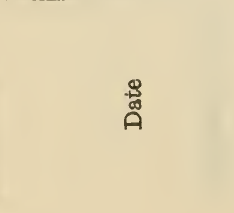 & & 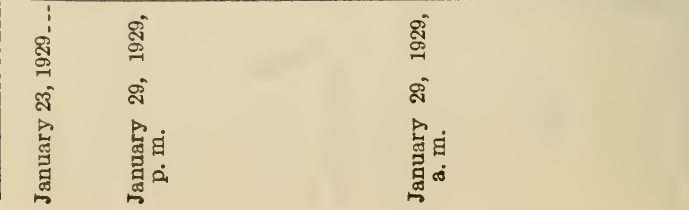 & \\
\hline
\end{tabular}


Column 12 shows a mean width of the distribution curve at the level of the static pressure as $70.4^{\circ} \pm 2^{\circ}$; the zonal angle is therefore $35^{\circ}$. The value estimated from the little information available on short cylinders by assuming the same relative effect of length-diameter ratio above the critical region of Reynolds numbers as observed below the critical region and by assuming the effective length-diameter ratio to be the same as if the cylinder were standing on an infinite plane surface, is $37^{\circ}$. The use of this estimated value would lead to force coefficients about 10 per cent lower than those given. The cylinder does not stand on an infinite plane surface, and its effective length-diameter ratio is therefore somewhat greater than 6 .

Column 16 shows the mean force coefficient obtained from the distribution to be $0.28 \pm 0.02$, while that obtained from the overturning moment is $0.39 \pm 0.04$. The local loading at an elevation of twothirds the height is therefore only about three-fourths the average loading on the whole stack. This is a somewhat greater difference than that shown in Figure 10 for the model experiments on cylinders of somewhat greater length-diameter ratios. It may be remarked that possible errors in the determination of the velocity pressure do not affect the relative values of the force coefficients, since the same value is used for the determination of the coefficients from the distribution and from the overturning moment. The greater difference between the two values for the experimental stack is probably associated with the smaller length-diameter ratio.

The value of 0.39 corresponds to a mean pressure on the projected area of the cylinder of $10 \mathrm{lbs} . / \mathrm{ft} .^{2}$ at a wind speed of 100 miles per hour. This figure is about one-half that commonly used in the design of chimneys. However, chimneys are much taller in proportion to their diameter than the experimental stack, and, therefore the results obtained on the short stack can not be applied to chimneys without some further justification. The object of the measurements on the experimental stack was to test a method of procedure for measurements on an actual chimney. The results of the test are reasonably satisfactory when the attendant circumstances are considered.

\section{POWER PLANT CHIMNEY}

On the occasion of the construction of a new power plant at the Bureau of Standards, provision was made for measuring the distribution of wind pressure on the stack at a single elevation, so that some information might be obtained as to the wind pressure on an actual chimney. The chimney is of radial brick, 200 feet from the foundation to the top of the chimney, the internal diameter at the top being 10 feet. The foundation is, however, considerably below the street level, and the top of the chimney is only about 120 feet above the highest part of the power plant building. A view of the stack and its surroundings taken from the East Building of the bureau and looking toward the northwest is shown in Figure 22, and a drawing is given in Figure 23. The parapet on the Northwest Building (the one to the left in fig. 22), on which the tower and wind vane are mounted, is about 88 feet below the top of the chimney. The elevation selected for the pressure observations is about 41 feet below the top, the external diameter of the chimney at this point being 11.8 feet. 
The dark line in Figure 22 running down the south side of the stack is caused by the group of 24 three-eighth inch brass pipes connecting the pressure holes with the observing room in the building. The pipes are under the ladder, which does not show in the reproduction. The pressure openings are located in a plane 2 feet above the top of the dark line, in a wide mortar joint indicated in the figure. A pipe

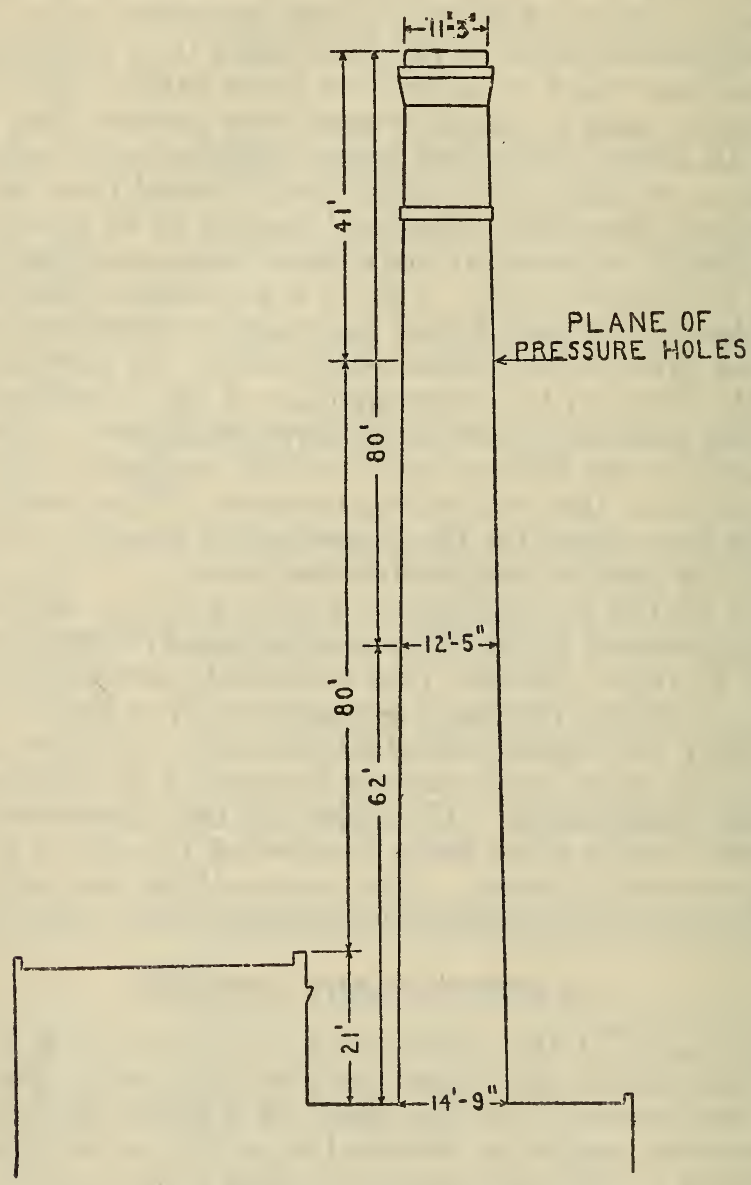

FIGURE 23.-Sketch of power plant chimney showing principal dimensions

runs from each opening to the interior of the chimney, thence around the inside of the chimney and down to the point of assembly, where all are brought outside and down under the ladder. The openings are simply the squared off ends of the three-eighth inch pipes. Precaution was taken to have no projections, the installation being supervised by one of the authors. The area around the pipes was pointed up. Notwithstanding these precautions the surface of the chimney is not a smooth surface, even around the holes, but in view of our experience with the experimental stack and with a model of 


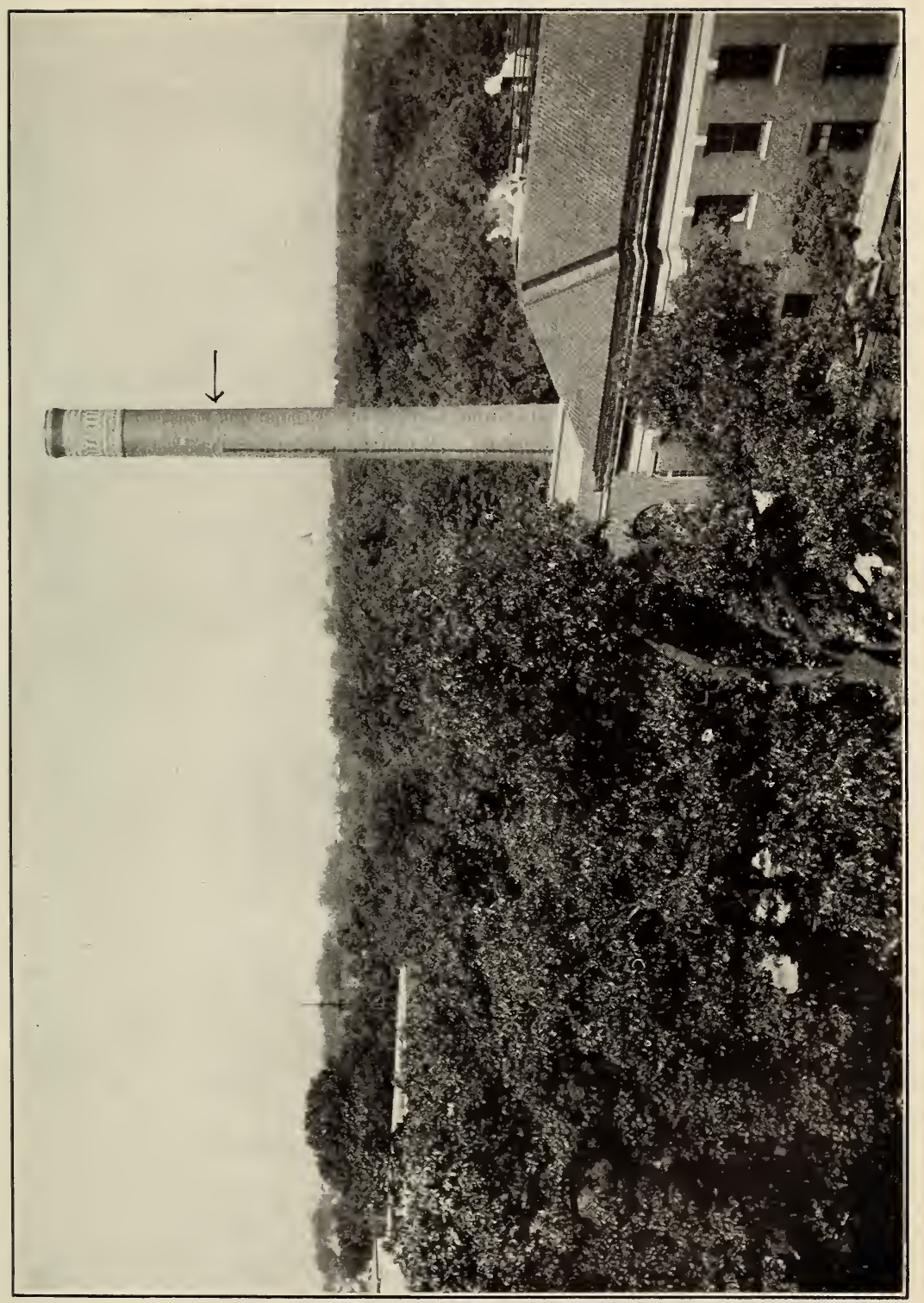

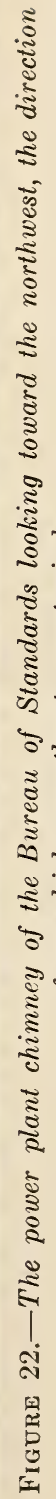


B. S. Journal of Research, RP221

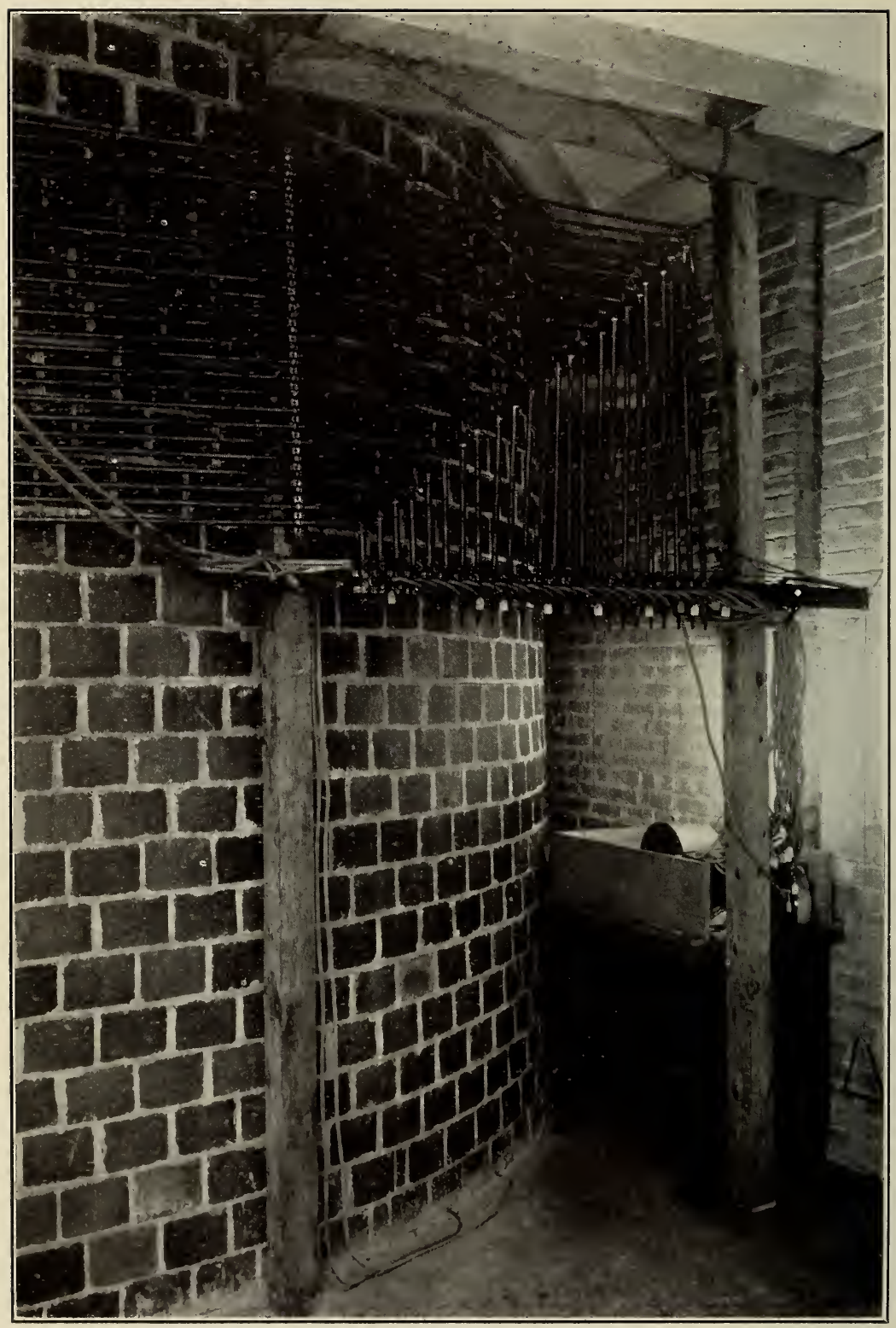

Figure 24.-The observer's station on the power plant chimney 
a part of the surface in the wind tunnel, the errors are not believed to be very great.

Besides the ladder running down the south side of the chimney and the 24 pipes, there is another projection on the north side, a lightning conductor leading from the lightning rods at the top of the chimney to the ground. The stack is slightly tapered as indicated in Figure 23, and there are certain projections in connection with the ornamentation at the top. The chimney is not, therefore, exactly a circular cylinder, its surface is not smooth and, in view of the surrounding topography (fig. 22), a determination of its effective length-diameter ratio is somewhat difficult. We may perhaps estimate the effective length-diameter ratio as roughly 15 to 20 , considering the chimney as equivalent to a 100 -foot stack standing on an infinite plane surface. From Table 4 and Figure 16 we would then estimate the zonal angle at which the pressure equals the static pressure as $31^{\circ}$.

An attempt was made to secure independent checks of the wind speed by means of a Pitot-static tube (the same used on the experimental stack and shown in fig. 18) mounted on a tower on the Northwest Building. (See fig. 22.) The Pitot-static tube was approximately 130 feet horizontally from the chimney and some 20 feet below the elevation of the pressure holes. The gauge was installed in the Northwest Building, and an electrically operated shut-off valve was connected to the trigger mechanism on the pressure distribution apparatus. Repeated series of observations have shown only a chance relation between the speed at the chimney and the speed at the wind gauge. One speed may be zero when the other is a maximum, or the two may occasionally vary together. In the case of the experimental stack where the wind gauge was only 20 feet from the pressure holes, the correlation was good. At six times this distance, there is no relation between the two speeds. The observing station is very similar to that described for the experimental stack. It is shown in Figure 24. The details of the mechanism do not show very clearly since one sees the 24 operating levers end on. The details of operation and of computation wore the same as described for the experimental stack. In general, however, the results have been computed in the form of averages of groups of points. A typical plot of a group of observations is shown in Figure 25.

The result of some nine groups of observations gives an average value of $0.37 \pm 0.02$ for the ratio of the average force per unit area of the projection to the pressure difference between the lee side of the chimney, $p_{r}$, and the maximum pressure $p_{\text {max }}$. Assuming the zonal angle at which the pressure is equal to the static pressure to be $31^{\circ}$, the ratio of $p_{\max }-p_{r}$ to the velocity pressure is found to be 1.82 , and hence the true shape coefficient $1.82 \times 0.37=0.67$, a value corresponding to a pressure of $17.1 \mathrm{lbs} . / \mathrm{ft}^{2}$ at a true wind speed of 100 miles per hour. This value is considerably higher than the value obtained on the short cylinder, a fact to be attributed mainly to the greater length-diameter ratio, but probably to some extent to the greater roughness of the actual chimney. 


\section{RÉSUMÉ}

In Figure 26 we have plotted for comparison the distribution around the 12.6-inch cylinder at section 6 obtained in the wind tunnel

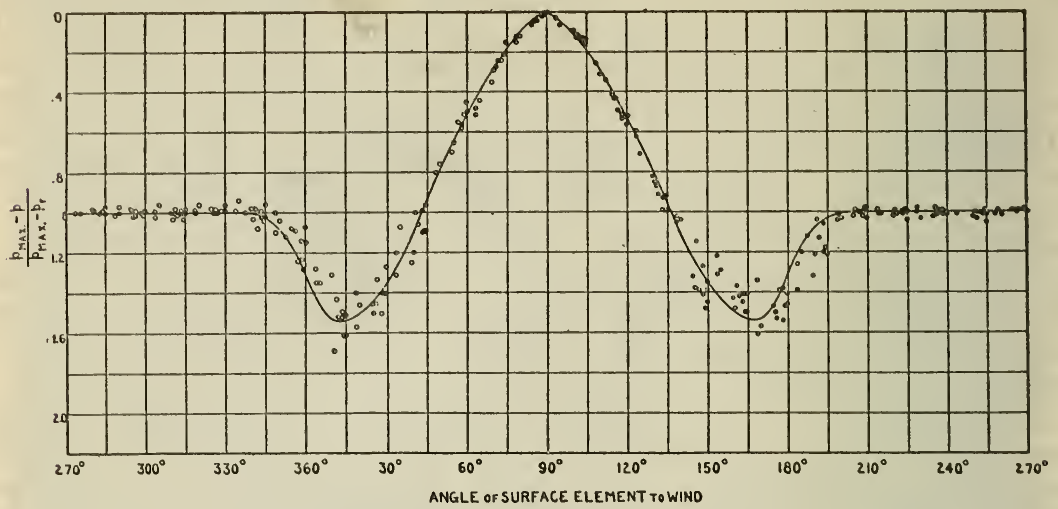

Figure 25.-Pressure distribution 41 fect from the top of the power-plant chimney, group of 12 runs

$p \quad=$ pressure on chimney.

$p_{\mathrm{max}}=$ maximum absolute pressure on chimney.

$p_{r} \quad=$ mean pressure on rear quarter of chimney.

All 41 feet from the top.

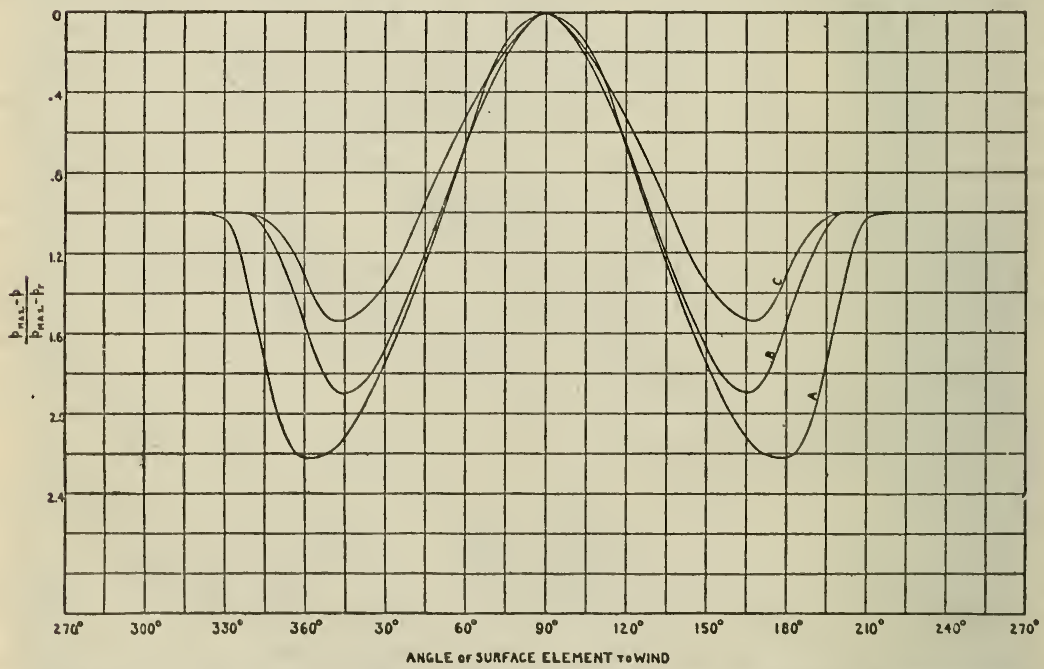

FIGUIR 26.-Comparison of distribution curves from model test, experimental stack, and power-plant chimney

\footnotetext{
$p \quad=$ pressure on chimney.

$p_{\mathrm{max}}=1 \mathrm{naximum}$ absolute pressure on chimney.

$p_{r}=$ mean pressure on rear quarter.

$A, 12.6$-inch eylinder in wind tunnel, distance from top $=1.4$ diameters.

$B, 10$ by 30 foot experimental stack, distance from top $=1$ diameter.

$C$, power-plant chimney, distance from top $=3.6$ diameters.
}

at a speed of $\mathrm{S} 0 \mathrm{ft} . / \mathrm{sec}$., the distribution around the 10 by 30 feet experimental stack, and the distribution around the power plant chimney, all expressed in terms of the difference between the pressure 
on the lee side and the maximum pressure. In Figure 27, the same curves are given in terms of the velocity pressure, known in the cases of the 12.6-inch cylinder and the 10 by 30 foot stack, but for the power plant chimney obtained on the assumption of a zonal angle of $31^{\circ}$ for the point at which the pressure equals the static pressure. The distributions are of the same general nature but very considerably different in detail.

The general conclusions to be drawn from our work are as follows:

1. The wind pressure on a chimney at a given wind speed is a function of the ratio of the height of the chimney to its diameter and possibly also of the roughness of its surface.

2. Model experiments can not be directly utilized in determining the force coefficients on chimneys because of the large effect of the size and speed as combined in the Reynolds number.

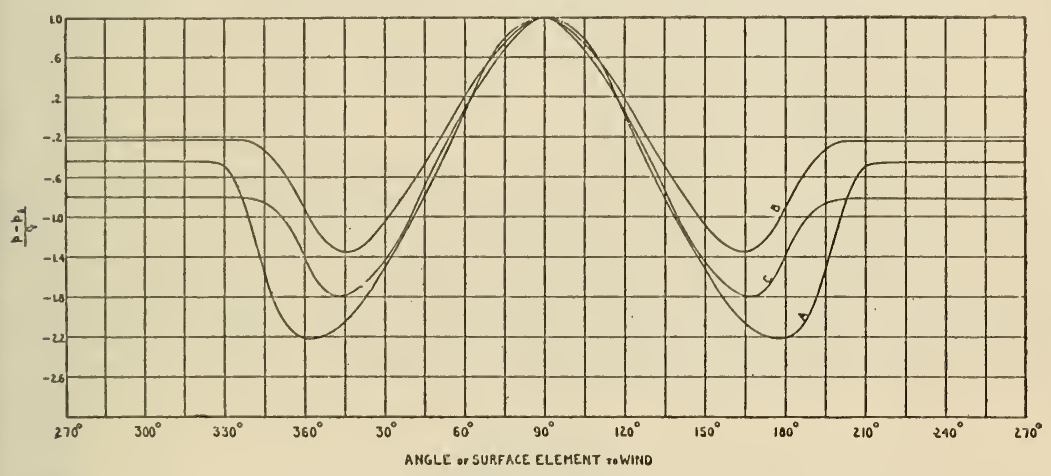

FIGURE 27.-Comparison of distribution curves from model test, experimental stack, and power plant chimney

$p=$ pressure on chimney.

$p_{s}=$ static pressure, $q=$ velocity pressure. For the power-plant chimney (curve $C$ ), $p_{s}$ is assumed to be equal to the value of $p$ at the zonal angle $31^{\circ}$.

$A, 12.6$-inch cylinder in wind tunnel, distance from to $\mathrm{p}=1.4$ diameters.

$B, 10$ by 30 foot experimental stack, distance from top=1.0 diameter

$C$, power-plant chimney, distance from top $=3.6$ diameters.

3. A wind pressure coefficient corresponding to $20 \mathrm{lbs}$./ft. ${ }^{2}$ of projected area at a wind speed of 100 miles per hour is a safe value for use in designing chimneys of which the exposed height is of the order of ten times the diameter and a reduction below this figure does not seem to be justified in the light of the results of our experiments when allowance is made for the fact that the pressure was measured at a single elevation.

4. Locally, the pressure may reach large values. This may need to be considered in the design of thin walled stacks of large diameter.

5. Further experiments are necessary for obtaining satisfactory information as to the variation of wind pressure with the ratio of height to diameter.

Washington, March 26, 1930. 